Fish And Fisheries

November 2017, Volume 18 Issue 6 Pages 1056-1072

http://dx.doi.org/10.1111/faf.12224

Achimer

http://archimer.ifremer.fr/doc/00409/52009/

(C) 2017 John Wiley \& Sons Ltd

\title{
Ecoviability for ecosystem-based fisheries management
}

\author{
Doyen Luc ${ }^{1,{ }^{*}}$, Bene Christophe ${ }^{2}$, Bertignac Michel ${ }^{3}$, Blanchard Fabian ${ }^{4}$, Cissé Abdoul ${ }^{4}$, \\ Dichmont Catherine ${ }^{5}$, Gourguet Sophie ${ }^{6}$, Guyader Olivier ${ }^{6}$, Hardy Pierre-Yves ${ }^{7}$, Jennings Sarah ${ }^{8}$, \\ Little Lorne Richard $^{9}$, Macher Claire ${ }^{6}$, Mills David Jonathan ${ }^{10,11}$, Noussair Ahmed ${ }^{12}$, Pascoe Sean ${ }^{5}$, \\ Pereau Jean-Christophe ${ }^{1}$, Sanz Nicolas ${ }^{4}$, Schwarz Anne-Maree ${ }^{10}$, Smith Tony, Thebaud Olivier ${ }^{5,6}$
}

${ }^{1}$ Univ Bordeaux, CNRS, GREThA, Pessac, France.

${ }^{2}$ CIAT, Decis \& Policy Anal Program, Cali, Colombia.

${ }^{3}$ IFREMER, Unite Sci \& Technol Halieut, Plouzane, France.

${ }^{4}$ UMSR Univ Guyane, LEEISA, CNRS, IFREMER, Cayenne, France.

${ }^{5}$ CSIRO, Oceans \& Atmosphere, Brisbane, Qld, Australia.

${ }^{6}$ Univ Brest, CNRS, IFREMER, Unite Econ Maritime,IUEM,AMURE,UMR 6308, Plouzane, France.

${ }^{7}$ Univ Montpellier 3, CEFE, CNRS, Montpellier, France.

${ }^{8}$ Univ Tasmania, Ctr Marine Socioecol, Hobart, Tas, Australia.

${ }^{9} \mathrm{CSIRO}$, Oceans \& Atmosphere, Hobart, Tas, Australia.

${ }^{10}$ WorldFish, Honiara, Solomon Islands.

${ }^{11}$ James Cook Univ, ARC Ctr Excellence Coral Reef Studies, Townsville, Qld, Australia.

${ }^{12}$ Univ Bordeaux, IMB, Bordeaux, France.

*Corresponding author : Luc Doyen, email address : luc.doyen@u-bordeaux.fr

\begin{abstract}
:
Reconciling food security, economic development and biodiversity conservation is a key challenge, especially in the face of the demographic transition characterizing many countries in the world. Fisheries and marine ecosystems constitute a difficult application of this bio-economic challenge. Many experts and scientists advocate an ecosystem approach to manage marine socio-ecosystems for their sustainability and resilience. However, the ways by which to operationalize ecosystem-based fisheries management (EBFM) remain poorly specified. We propose a specific methodological framework-viability modelling-to do so. We show how viability modelling can be applied using four contrasted case-studies: two small-scale fisheries in South America and Pacific and two larger-scale fisheries in Europe and Australia. The four fisheries are analysed using the same modelling framework, structured around a set of common methods, indicators and scenarios. The calibrated models are dynamic, multispecies and multifleet and account for various sources of uncertainty. A multicriteria evaluation is used to assess the scenarios' outcomes over a long time horizon with different constraints based on ecological, social and economic reference points. Results show to what extent the bio-economic and ecosystem risks associated with the adoption of status quo strategies are relatively high and challenge the implementation of EBFM. In contrast, strategies called ecoviability or co-viability strategies, that aim at satisfying the viability constraints, reduce significantly these ecological and economic risks and promote EBFM. The gains associated with those ecoviability strategies, however, decrease with the intensity of
\end{abstract}


regulations imposed on these fisheries.

Keywords : biodiversity, ecological economics, ecosystem approach, fisheries, scenario, viability 


\section{Contents}

\section{Introduction and motivations}

\section{Ecoviability approach, models and scenarios}

2.1 A multi-species multi-feet dynamic model . . . . . . . . . . . . . . .

2.2 The ecoviability objectives $\ldots \ldots \ldots \ldots \ldots \ldots$

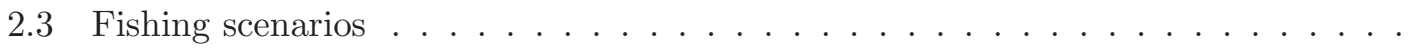

2.4 Ecological and economic metrics

3 Results as a synthesis of different case studies

3.1 Case studies . . . . . . . . . . . . . . . . . . .

3.2 Formalization and calibration of models for the case studies . . . . . . . . . .

3.3 Viability constraints of the case studies $\ldots \ldots \ldots \ldots$

3.4 Ecoviability scenarios . . . . . . . . . . . . . . . . .

3.5 Viability performances of scenarios $\ldots \ldots \ldots \ldots$

3.6 Synergy or tradeoff between risk and economic expectations . . . . . . . . . . . .

3.7 Viable effort or vessels reallocation . . . . . . . . . . . . . . . .

\section{Discussion}

4.1 Ecoviability is globally well suited to EBFM.

4.2 Ecoviability allows models of intermediate complexity adapted to EBFM . . . . .

4.3 Ecoviability directly deals with sustainability

4.4 Ecoviability provides an adaptive management with respect to uncertainties . . .

4.5 Ecoviability can capture the dynamics of biodiversity . . . . . . . . . . .

4.6 Ecoviability can represent the short term vs. long term choices . . . . . . . . .

4.7 Ecoviability can allow underlining the role of technical change . . . . . . . . . .

4.8 Ecoviability can rely on many fisheries management tools . . . . . . . . . . . 
Ecoviability

\section{Conclusions}




\section{Introduction and motivations}

Reconciling food security with biodiversity conservation is among the greatest challenges of the century, especially in the face of the world demographic transition (Godfray et al., 2010; Rice \& Garcia, 2011). The creation of the IPBES (International Panel for Biodiversity and Ecosystem Services) at the interface between decision support and scientific knowledge is in direct line with these concerns. Implementing this bio-economic perspective is especially challenging in the case of fisheries and marine ecosystems. Marine and coastal ecosystems are experiencing accelerating changes affecting species and communities at different biotic scales, sometimes with alarming trends and largely unknown consequences (Butchart et al., 2010; MEA, 2005). These changes are partially due to past and current fishing pressure, thus questioning the sustainability of current fishing activities and food production systems, and raise key questions in terms of food security, especially for developing countries with high demographic growth. Climate change complicates and exacerbates the issues by inducing new, or intensifying existing, risks, uncertainties and vulnerabilities.

As a consequence, ensuring the long-term ecological-economic sustainability of marine fisheries systems, and preserving the marine biodiversity and ecosystems that support them, have become a major issue for national and international agencies (FAO, 2013). In response, an increasing number of marine scientists and experts advocate the use of ecosystem-based fishery management (EBFM) accounting for the various ecological and economic complexities at play. Pikitch et al. (2004) for instance claim that EBFM is a new direction for fishery management, essentially reversing the order of management priorities so that management starts with the ecosystem rather than a target species, while FAO (2003) proposes the following definition:

"An ecosystem approach to fisheries strives to balance diverse societal objectives, by taking into account the knowledge and uncertainties about biotic, abiotic and human components of ecosystems and their interactions and applying an integrated approach to fisheries within ecologically meaningful boundaries."

The way to operationalize this EBFM approach, however, remains challenging (Sanchirico et al., 2008; Doyen et al., 2013), along with the identification of methods, approaches and tools 
Ecoviability

to support its implementation. Hence, there is a need to develop new models, indicators and scenarios in this domain (Plagányi et al., 2007). In particular, the effectiveness of current regulatory instruments including fishing quotas or financial incentives needs to be reconsidered in light of this new multi-functional, cross-sectoral and interdisciplinary context, accounting for the multiple commodities and services provided by marine biodiversity and ecosystems. The aim of this paper is to contribute to this discussion through the use of viability modelling.

Viability modeling is now recognized by a growing number of researchers (Jennings, 2005; Cury et al., 2005; Thébaud et al., 2013; Krawczyk et al., 2013) as a relevant framework for EBFM. In the context of dynamic systems, the aim of the viability approach is to explore states and controls that ensure the 'good health' and safety of the system (Aubin, 1990; De Lara \& Doyen, 2008). By identifying the viability conditions that allow constraints to be fulfilled over time, considering both present and future states of a dynamic system, the viability approach conveys information on sustainability (Baumgartner \& Quaas, 2009). It accounts for dynamic complexities, uncertainties, risks and multiple sustainability objectives. Resilience and recovery goals can also be addressed through viability modeling using the notion of minimal time of crisis (Béné et al., 2001; Deffuant \& Gilbert, 2011). As reviewed recently by Schuhbauer \& Sumaila (2016), the approach has already been successfully applied to fisheries management in several contexts (Eisenack et al., 2006; Martinet et al., 2007; Sanogo et al., 2013; Krawczyk et al., 2013) including (eco)-system or biodiversity dynamics (Mullon et al., 2004; Doyen et al., 2007; DeLara et al., 2012; Gourguet et al., 2013; Maynou, 2014). In relation to food security, Cissé et al. (2013, 2015); Hardy et al. (2013) provide useful bio-economic insights in the context of developing countries under important demographic pressure.

The main objective of this paper is to show through modeling and scenario analyses how this viability approach can provide a relevant methodological framework to implement EBFM. The work relies especially on four contrasted case studies: the small-scale fishery of French Guiana (South America), the small-scale fishery of Solomon Islands (Pacific), the Bay of Biscay multispecies demersal fishery (Europe) and the Northern prawn fishery of the Gulf of Carpenteria (Australia). All four fisheries are represented as systems of intermediary complexity (Plagányi et al., 2014) and analyzed using the same modeling framework, common methods, indicators 
and scenarios. The calibrated models are dynamic, multi-species and multi-fleet and account for various sources of uncertainty. A multi-criteria analysis of alternative effort strategies is implemented, with the objective to assess the fulfillment of different constraints and objectives at the 2030-2050 horizon, based on ecological, social and economic reference points. We name such an approach ecoviability as in Cissé et al. (2015) to highlight the ecological, economic and ecosystemic ingredients of this viability modeling.

The scientific contribution of the paper is twofold. First it demonstrates the advantages of using the ecoviability approach to operationalize EBFM through a series of contrasted case studies. In particular it shows how implementing a viability strategy can lead to 'win-win' situations in terms of reduction of ecological and economical vulnerabilities and risks. Second, the paper highlights some potentially important differences between more heavily regulated and less regulated fisheries when comparing a viability strategy to the current state (status quo). Ecoviavility indeed leads to 'win-win' outcomes in terms of both economic expectation and bio-economic risk for less regulated fisheries while, in contrast, heavily regulated fisheries face trade-offs because they perform well in terms of economic expectation and scores.

The paper is organized as follows. Section 2 presents the generic ecoviability modeling approach including the controlled uncertain dynamics, viability metrics and scenarios. Section 3 is devoted to the application of the general framework to the contrasted case studies and especially to the comparison of scenarios including the viability scenario. Section 4 discusses the results in particular with respect to EBFM while Section 5 concludes. Mathematical details on the models and methods are described in the Appendix.

\section{Ecoviability approach, models and scenarios}

The viability approach relies on mathematical models derived from the theory of dynamic systems control under constraints. Within this generic framework, the ecoviability framework (also termed co-viability) specifically focuses on the ecological-economic viability of exploited ecosystems including fisheries and marine resources. In this section, the generic framework that underlies ecoviability modeling in the four case studies is presented. The common mathematical 
Ecoviability

framework allows us to consider the problem of integrating multi-species, multi-fleet, dynamic and uncertain socio-ecological systems while taking into account ecological and economic viability goals or constraints which all constitute major ingredients for EBFM.

\section{$2.1 \quad$ A multi-species multi-feet dynamic model}

Marine social ecological systems are described by a set of $n$ marine stocks exploited by $m$ distinct fleets. A state space formulation (Clark \& Mangel, 2000) in discrete time is used to represent the evolution of the ecosystem. Thus the $n$ stocks whose states at time $t$ are denoted by $x_{i}(t)$ are governed by the following controlled and uncertain dynamic equations

$$
x_{i}(t+\Delta t)=g_{i}(x(t), e(t), \omega(t)),
$$

from initial time $t=t_{0}$ to temporal horizon $t=T$ with time step $\Delta t$. The states $x_{i}(t)$ can potentially be vectors of abundance or biomass at different ages or sizes or by sex. The global state $x(t)$ representing the community or ecosystem state is the vector of states $x(t)=\left(x_{1}(t), \ldots, x_{n}(t)\right)$. The vector $e(t)=\left(e_{1}(t), \ldots, e_{m}(t)\right)$ is the control of the system through the effort (duration or number of vessels) of the different fleets at time $t$. Alternatively, output controls through catches could be used based on production functions as described below in equation (2). The variables $\omega(t)=\left(\omega_{1}(t), \ldots, \omega_{p}(t)\right)$ represent the uncertainties affecting the dynamics of the system through random fluctuations on species growth or recruitment, species interactions and catchabilities. The growth functions $g_{i}$ for each species (or groups of species) may account for inter-specific competition and/or trophic interactions.

The catches $h_{i j}(t)$ of stocks $x_{i}(t)$ by fleet $j$ depend on fishing effort $e_{j}(t)$ through the production function

$$
h_{i j}(t)=h_{j}\left(x_{i}(t), e_{j}(t), \omega(t)\right) .
$$

The harvest function $h_{j}=\left(h_{1 j}, \ldots, h_{i j}, \ldots, h_{n j}\right)$ of every fleet $j$ accounts for the technical interactions and bycatch which may occur and complexify the control of the system. Catches can also be uncertain (depending on $\omega(t)$ ) because of random catchability for instance. See 
appendix, sections A.3, A.4, A.5 and A.6 for more details for each case study.

\section{$2.2 \quad$ The ecoviability objectives}

The viability approach focuses on the safety and feasibility of controlled dynamics of the system with respect to constraints or targets representing the good health, safety or sustainability of the socio-ecosystem. These constraints can involve ecological thresholds as in the case of an extinction threshold in population viability analysis (PVA) (Morris \& Doak, 2003). Economics constraints (guaranteed rent, food security, ...) can also be integrated as recently reviewed in Schuhbauer \& Sumaila (2016), thus allowing for multi-criteria and bio-economic analyses. Such integrated viability objectives generally refer to a mix of the following ecological and economic constraints.

First, an ecological requirement is considered through biological or ecological indicators $\operatorname{Bio}(x(t), \omega(t))$ as follows:

$$
\operatorname{Bio}(x(t), \omega(t)) \geq \text { Biolim }_{\text {lim }}
$$

The ecological indicators $\operatorname{Bio}(x(t), \omega(t))$ correspond to biodiversity or biological metrics which may typically encompass species richness, trophic index or measure of spawning biomass for structured populations. They can also be uncertain because of stock measurement errors or because of uncertainty with regard to ecological thresholds in fish population viability or in fish communities. In that context, the threshold Biolim can stand for an ecological tipping point.

Second a food security objective is taken into account through the aggregated catch $H(t)=$ $\sum_{i, j} h_{i, j}(t)$ which plays the role of food supply. Maintaining the food supply high enough with respect to the demand reads

$$
H(t) \geq H_{\lim }(t)
$$

where $H_{\lim }(t)$ refers to some basic need threshold which may be time-dependent typically because of demographic growth.

Third, economic viability is captured through profitability of the fleets as follows

$$
\operatorname{Profit}_{j}(t) \geq 0 \text {. }
$$


Here the economic value $\operatorname{Profit}_{j}(t)=\operatorname{Profit}_{j}(x(t), e(t), \omega(t))$ relates to the profit of each fleet $j$ computed as the difference between the revenues $\operatorname{Inc}_{j}(t)$ derived from catches $h_{j}(t)$ and operating $\operatorname{costs} c_{j}(t)$ associated with the fishing effort $e_{j}(t)$; namely

$$
\operatorname{Profit}_{j}(t)=\operatorname{Inc}\left(h_{j}(t), \omega(t)\right)-c_{j}\left(e_{j}(t), \omega(t)\right) .
$$

Note that these income and cost values are also potentially affected by random uncertainties $\omega(t)$ because of market price and cost (e.g. fuel) fluctuations.

Such an ecoviability framework integrating biodiversity, productive and profitability requirements helps overcome the apparent antagonism between ecology, often concerned with survival and conservation issues, and economic considerations, usually centered around the pursuit of optimality and profitablity (see below). In the bio-economic context, strong links have been shown to exist between viability approaches and notable steady states such as Maximum Sustainable Yield (MSY) or Maximum Economic Yield (MEY) (Béné et al., 2001), the Rawlsian 'maximin' approach (Doyen \& Martinet, 2012) or precautionary approaches (DeLara et al., 2007). A key mathematical tool for the analysis of viability is provided by the so-called viability kernel as illustrated by figure A.4 in the Appendix. The viability kernel corresponds to a safe space within the initial set of constraints where the system needs to remain to be viable and to remain so in the future. It exemplifies the need for anticipating viability crisis.

In contexts where uncertainties have a probabilistic nature, bio-economic viability can be defined as the fulfillment of constraints with a high enough probability (Doyen \& De Lara, 2010); namely

$$
\mathbb{P}\left(\text { Constraints }(3),(4),(5) \text { are fulfilled for } t=t_{0}, . ., T\right)>\beta
$$

\footnotetext{
where $\beta$ corresponds to some prescribed confidence rate $(99 \%, 90 \%, \ldots)$ and where the probability $\mathbb{P}$ is computed with respect to the uncertainty $\omega$ which summarizes stochasticities on communities dynamics (growth, species interactions), catchabilities or technical interactions, costs or prices.
} 


\subsection{Fishing scenarios}

We assume that the historical trajectories of the system are given by a sequence of states $x(t)$ and controls $e(t)$ until a current time denoted by $t_{0}$. By contrast, effort scenarios consist in sequences $e\left(t_{0}\right), \ldots, e(T)$ from current time $t_{0}$ to horizon $T$ (typically $T=2050$ ).

The first scenario of interest for the analysis is the 'baseline' (or status quo) scenario (SQS), where the control remains fixed at the level it is at $t_{0}$ :

$$
\text { SQS: } \quad e(t)=e\left(t_{0}\right) \text { for } t=t_{0}, . ., T
$$

The second scenario considered is the scenario that aims at maximizing the expected net present value of fishery returns. This scenario, denoted by NPVS is defined as follows:

$$
\text { NPVS: } \quad \max _{e\left(t_{0}\right), \ldots, e(T)} \operatorname{NPV}(e)
$$

where net present value $\operatorname{NPV}(e)$ of a scenario of efforts $e=e\left(t_{0}\right), \ldots, e(T)$ is defined by

$$
\operatorname{NPV}(e)=\mathbb{E}\left(\sum_{t=t_{0}}^{T} \rho^{t} \sum_{\text {fleets } j} \operatorname{Profit}_{j}(t)\right) .
$$

Here $\mathbb{E}$ refers to the expected value of returns with respect to uncertainty $\omega$ and $\rho$ stands for the discount factor. The numerical method to compute this expected value and the optimal controls are detailed in the following section 2.4 devoted to metrics and in the Appendix A.1. Such a strategy turns out to be close to a dynamic MEY (maximum economic yield) strategy in the long run (Clark, 1990).

The third scenario, denoted hereafter by EVS, is the ecoviability scenario which corresponds to the strategy that maximizes the probability that the system remains viable from $t_{0}$ to horizon $T$ with respect to the control (the fishing effort $e(t)$ ); namely

$$
\text { EVS: } \quad \max _{e\left(t_{0}\right), \ldots, e(T)} \mathbb{P}\left(\text { Constraints }(3),(4),(5) \text { are fulfilled for } t=t_{0}, . ., T\right) .
$$

181 Such a formulation points to the fact that the viability approach, in a stochastic context, consists 
in minimizing bio-economic risk or vulnerability. The appropriate effort strategies which ensure the viability of the system as solutions of the maximal viability problem (10) are given by feedback controls in the form of $e(t, x)$. This is due to the dynamic programming structure underlying the probabilistic viability problem, as stressed in Doyen \& De Lara (2010). Such strategies enable adaptive management, accounting for uncertainties affecting the entire socialecological system. The numerical method to compute this ecoviability probability value and the viable controls are detailed in the following section 2.4 devoted to metrics and in Appendix A.2. The scientific software SCILAB (http://www.scilab.org/en) has been used for both probabilistic simulations and optimization computations.

\subsection{Ecological and economic metrics}

This subsection introduces the metrics that will be used for the analysis and the comparison of the scenarios. The scores especially focus on ecological or economic viability probabilities and net present values ratio.

Net present value: The normative scenario NPVS defined in (8) is based on the expected net present value defined by

$$
\operatorname{NPV}(e, \omega)=\sum_{t=t_{0}}^{T} \rho^{t} \sum_{\text {fleets }}^{j} \operatorname{Profit}_{j}(t) .
$$

The numerical approximation of the expected value first relies on the mean over a finite number of replicates of the random variables $\omega($.$) underlying the uncertainties. In other words, we$ consider the following $K$ replicates $\omega_{k}($.$) of random variables \omega($.$) over time t_{0}, \ldots, T$

$$
\left\{\begin{array}{c}
\omega_{1}\left(t_{0}\right), \ldots, \omega_{1}(T) \\
\vdots \\
\omega_{K}\left(t_{0}\right), \ldots, \omega_{K}(T),
\end{array}\right.
$$


and we approximate the expected value by its mean over the $K$ replicates as follows

$$
\mathbb{E}_{\omega}(\operatorname{NPV}(e, \omega)) \approx \frac{1}{K} \sum_{k=1}^{K} \operatorname{NPV}\left(e, \omega_{k}\right)
$$

In order to compare the different case studies, the net present values are homogenized in the sense that the ratio between the net present value of every scenario and the maximal net present value (related to the NPVS) is computed as follows:

$$
\operatorname{INPV}(e)=\frac{\operatorname{NPV}(e)}{\operatorname{NPV}\left(e^{N P V S}\right)}
$$

where net present value is defined in equation (9) and $e^{N P V S}$ stands for the optimal effort of the net present value scenario NPVS. Thus this ratio INPV is smaller than 1 in every case study. It takes the value 1 for the NPVS effort strategy.

Viability probability scores: The ecoviability probability underlying scenario EVS defined in (10) is computed in a similar way using the fact that the probability is the expected value of an indicator (boolean) function. More specifically, we rewrite the viability probability as follows

$$
\mathbb{P}\left(\text { Constraints }(3),(4),(5) \text { are fulfilled for } t=t_{0}, . ., T\right)=\mathbb{E}\left[\prod_{t=t_{0}}^{T} \mathbf{1}_{C}(x(t), e(t), \omega(t))\right]
$$

with the indicator function

$$
\mathbf{1}_{C}(x, e, \omega)= \begin{cases}1 & \text { if constraints }(3),(4),(5) \text { are satisfied } \\ 0 & \text { otherwise. }\end{cases}
$$

Ecological viability probability $\mathbb{P}\left(\right.$ Constraint (3) are fulfilled for $\left.t=t_{0}, . ., T\right)$ and economic viability probability $\mathbb{P}\left(\right.$ Constraints (5) are fulfilled for $\left.t=t_{0}, . ., T\right)$ that will be used in the comparison of scenarios are particular instances of the general viability probability computed in $(12)$. 
Biodiversity metrics The ecological viability probability relies on biological, ecological or biodiversity indicators. The choice of biodiversity metrics remains the subject of numerous debates, with indicators ranging from structural indices, taxonomic or functional indicators to emblematic species. Regarding ecoviability studies for stylized models involving global biomass or abundances of species, the species richness index, the marine trophic index and the Simpson indicator have been used. The species richness denoted by SR is computed as follows:

$$
\mathrm{SR}(t)=\sum_{i} \mathbf{1}_{i}\left(x_{i}(t)\right)
$$

with the boolean function

$$
\mathbf{1}_{i}(x)= \begin{cases}1 & \text { if } x \geq B_{\lim , i} \\ 0 & \text { otherwise }\end{cases}
$$

The marine trophic index $\operatorname{MTI}(t)$ of an ecosystem is computed as follows

$$
\operatorname{MTI}(t)=\frac{1}{N(t)} \sum_{i=1} T_{i} N_{i}(t) \quad \text { with abundances } N_{i}(t)=\frac{x_{i}(t)}{v_{i}}
$$

where $v_{i}$ is a fixed average weight by species and $T_{i}$ is the trophic level of species $i$. The Simpson index SI complements the SR index by estimating the probability that two individuals belong to the same family or species.

For structured models, the use of indicators associated with the ICES precautionary approach and thresholds for the spawning biomass of fish populations gave important insights into the risks of stock collapse.

\section{Results as a synthesis of different case studies}

Ecoviability approach, models and scenarios constitute the original contribution of the paper. This section shows in particular the interest of such ecoviability modeling to operationalize EBFM by bringing together and comparing the bio-economic models and viability scenarios of four contrasted case studies including the small-scale fishery of French Guiana (South America), the small-scale fishery of Solomon Islands (Pacific), the Bay of Biscay multi-species demersal 
Ecoviability

fishery (Europe) and the Northern prawn fishery of the Gulf of Carpenteria (Australia). In this section, the different case studies and EBFM contexts are first presented. Then the formalization of the viability modeling approach for all case studies is described. The specific features of the systemic and mechanistic models as well as the specific viability constraints related to the four case studies are then listed. Bio-economic performances of viability scenarios for two case studies are then compared graphically. Then it is shown how implementing a viability strategy can lead for the four case studies to 'win-win' situations in terms of reduction of ecological and economical risks. The paper also highlights some important differences of ecoviability scenarios between more heavily regulated and less regulated fisheries in terms of economic risk as well as effort reallocation. The viability models, scenarios and performances of these examples are detailed in Doyen et al. (2012); Gourguet et al. (2013, 2014, 2015); Cissé et al. (2013, 2015); Hardy et al. (2013).

\subsection{Case studies}

The geographical diversity of the four case studies involved in the analysis, ranging from South America, Pacific, Europe to Australia, is useful to obtain generic findings. The following paragraphs briefly describe the major features of these fisheries. Particular emphasis is put on ecosystem challenges for these fisheries following Pitcher et al. (2009). While achieving EBFM is a major objective for fisheries worldwide, these case studies exemplify the extent to which the degree of EBFM implementation can significantly vary across countries. In that regard, the description of the main differences and common features between these four case studies is informative (Table 1). In particular, two groups can be distinguished: small scale (and coastal) fisheries in Solomon islands and French Guiana; large scale (and more industrial) fisheries for the Bay of Biscay and the Northern Prawn Fisheries.

French Guiana Fishery: The small-scale fishery operating along the coast of French Guiana in South America is a multi-species and multi-fleet fishery landing about 3000 tonnes per year worth $€ 9$ million ( $\approx$ US $\$ 9.78$ million). Daily bio-economic data have been recorded by IFREMER since 2006 (Cissé et al., 2013). The fishery, which is highly diverse with about 30 
Ecoviability

exploited species such as weakfish species (Cynoscion acoupa, C. virescens, C. steindachneri, Sciaenidae), sea catfish species (Sciades proops, S. parkeri, Notarius grandicassis, Ariidae), grunts (Anisotremus surinamensis, Genyatremus luteus, Haemulidae), snooks (Centropomus undecimalis, C. parallelus, Centropomidae), Giant grouper (Epinephelus itajara, Serranidae) and shark plays a key socio-economic role for the local population, both in terms of livelihood and food security. Recent demographic projections however indicate a likely doubling of the local human population by 2030. Demand for local fish is therefore expected to increase substantially, with some potential risk for the sustainability of the fishery and the local ecosystem's biodiversity. The evaluation based on the Rapfish method proposed in Cissé et al. (2014) of the status of this coastal fishery in terms of EBFM rates it a medium score and points to areas of potential improvement among which discarding and capacity building of the supply chain are important.

Bay of Biscay Mixed Fishery: The Bay of Biscay demersal fishery is a multi-fleet, multigear fishery targeting several species including Norway lobster (Nephrops norvegicus, Nephropidae), European hake (Merluccius merluccius, Merlucciidae), Anglerfish and Blackbellied anglerfish (Lophius piscatorius and L. budegassa, Lophiidae) and Common sole (Solea solea, Soleidae) with high commercial values (Gourguet et al., 2013). Its turnover amounted to $€ 200$ million $(\approx$ US\$ 217 million) in 2009. The fishery, however, is under strong pressure, with several stocks already fully exploited. The fishery also operates within a context of high uncertainty with regard to economic costs and biological dynamics. Additional management complexities are induced by the many technical interactions associated with the multi-fleet nature of the activities (trawlers, gillnets). Maintaining the bio-economic sustainability of these different components is thus difficult. A multi-annual management plan based on the recent European Common Fisheries Policy (CFP) reform aims to achieve Maximum Sustainable Yield for all stocks before 2020 subject to economic and social viability constraints. In addition, implementing the recently adopted landing obligation (decided at the European scale) is a major challenge for this mixed fishery. The fishery is managed by technical measures, access and quota regulations. Pitcher et al. (2009) globally scored France a ' fail grade' in their evaluation of progress in implementing EBFM. 
The Australian Northern prawn fishery: The Northern prawn fishery is one of Australia's most valuable fisheries in terms of total landed value with AU $\$ 91.6$ million $(\approx$ US $\$ 71$ million) in 2009-2010 involving 52 trawlers since 2007 (Punt et al., 2010). This multi-species and multi-fishing strategies trawl fishery targets several high-value species of tropical prawns, each with different dynamics and levels of biological variability. The bulk of revenue is obtained from high-valued but rather unpredictable white banana prawns (Fenneropenaeus merguiensis, Penaeidae) and two species of tiger prawns (Grooved tiger prawn, Penaeus semisulcatus, and Brown tiger prawn, Penaeus esculentus, Penaeidae). The fishery's management objective is to maximize economic yield, while accounting for biodiversity impacts. According to Pitcher et al. (2009), Australian fisheries are well advanced in achieving EBFM. Furthermore, in certifying the Northern prawn fishery in November 2012, the MSC (Marine Stewardship Council) acknowledged efforts to limit fishing impacts on the ecosystem, although some concerns remain. Indeed, while the mandatory introduction of Turtle Excluder Devices (TEDs) and By-catch Reduction Devices (BRDs) played a major role in the MSC accreditation by significantly reducing by-catch species such as turtle, syngnathid and sawfish, it only reduced the catches of sea snakes by $5 \%$.

Solomon Islands Fishery: Solomon Islands are located at the extreme east of the coral triangle in the Pacific. This region shelters the highest level of marine biodiversity in the world (Burke et al., 2012). The most recent Solomon Islands biodiversity assessment for instance accounted for more than one thousand fish species for these islands (Green et al., 2006). While nearly all coastal dwellers fish for subsistence and self-consumption, an increasing number of them now also engage in income-generating fishing activities. The most recent value of Solomon catches (Brewer, 2011) estimates it at US\$21 million. This dual function (subsistence and cash-generation) makes small-scale coastal fisheries a crucial element of the local socio-economic system. Yet, the population of Solomon Islands has doubled in the last 20 years. This demographic trend and the subsequent increase in demand for fish, along with the increased marketing of the output impose a growing pressure on marine resources and on the local ecosystem. The pressure is especially strong on some key species such as groupers (Serranidae), parrotfish (Scaridae) and particularly on sea-cucumbers' species (Holothuroidea). To deal with such issues, a 
Ecoviability

community-based approach (Govan et al., 2009) in line with the implementation of EBFM has been promoted for the last 30 years. In that respect, WorldFish Center (2010) shows several lessons of successful applications of EBFM in the main islands of the country.

\subsection{Formalization and calibration of models for the case studies}

The formalization of the four different bio-economic models used for the viability analyses has been carried out following the generic modeling framework described in Section 2 and especially the multi-species multi-fleet stochastic dynamics (1). However, beyond this common mathematical framework, two different approaches have been used regarding this formalization: For the case studies of demersal mixed fishery of the Bay of Biscay and the Northern prawn fishery in Australia, models were derived from available structured models (in class or age). In Solomon Islands and French Guiana case studies for which no assessments were available, stylized bioeconomic models based on the global biomass of species (or groups of species) were developed. The specific features of the systemic and mechanistic models related to the four case studies are detailed in the four paragraphs below. They are also listed and compared in Table 2. More mathematical details on the models are also provided in Appendices A.3, A.4, A.5 and A.6.

The parameterization of the four different models has also been achieved following two distinct approaches. For the case studies of demersal mixed fishery of the Bay of Biscay and the Northern prawn fishery in Australia, calibrations were derived from available stock assessments and economic data. In Solomon Islands and French Guiana case studies for which no assessments were available, specific stock and bio-economic models were developed and fitted to the available data. To validate the models and to show to what extent the estimated trajectories fit the observed trajectories, graphs are displayed in the Appendix sections A.3, A.4, A.5 along with figures A.1, A.2, A.3. A comparison of the estimated parameters, their number and underlying data is provided at the bottom of Table 2 .

French Guiana: The fishery population dynamics model used in this case is a multi-species, multi-fleet dynamic model in discrete time (Cissé et al., 2013, 2015). The model accounts for trophic interactions between 13 exploited species and a fourteenth stock aggregating other marine 
Ecoviability

resources. The biomass of the species are assumed to be governed by a complex dynamic system based on Lotka-Volterra trophic relationships and fishing effort of the different fleets. Daily observations of catches and fishing efforts from the landing points all along French Guiana's coast, available from January 2006 to December 2009, were used to calibrate the model. Estimations of the parameters were carried out using a least-square method minimizing the distance between observed and estimated catches. Data from the literature (Leopold, 2004) and Fishbase (http://www.fishbase.ca/) were used to provide qualitative trophic information concerning the sign of the relationship between species and intrinsic growth rates, and to initiate parameter estimations.

Demersal mixed fishery of Bay of Biscay: As detailed in Doyen et al. (2012) and Gourguet et al. (2013), population dynamics of the three species included in the analysis (hake, nephrops and sole) were modeled using an age-structured population model. Parameters were derived from stock assessments carried out by ICES (2009) using a virtual population model (Darby \& Flatman, 1994; Shepherd, 1999). The dynamic model was then fitted for each species separately, using data on catch and abundance from surveys or derived from commercial CPUEs.

Northern prawn fishery of Australia: As described in Gourguet et al. (2014) and Gourguet et al. (2015), three species of prawns were modeled using a size-structured population model that operates on a weekly time-step. The parameters of this multispecies population model were estimated using data on catches and effort, catch rates, as well as length frequency data from both surveys and commercial landings (Punt et al., 2010).

Solomon Islands: As in the French Guiana case study, the states of the stock are defined in terms of the global biomass of different groups of species. The model is a multi-group, multi-fleet dynamic model (Hardy et al., 2013) which accounts for trophic interactions between exploited species. The dynamics of the 8 groups included in the model is described through a Lotka-Volterra trophic model accounting for fishing mortality from the several fleets involved in the fishery. Different sources of information were used to parameterize the model. For the sea cucumber and coral fish groups, parameters were calibrated based on data extracted from the 
Ecoviability

literature including Green et al. (2006) and FishBase. The parameterization of the model for skipjack was carried out in two steps. First, a Western Pacific assessment (Langley \& Hampton, 2008) was used to estimate the industrial fishery's parameters. Then, the model including all fleets (industrial and artisanal) was fitted to data on catches from 1982 to 2006.

\subsection{Viability constraints of the case studies}

The different types of constraints applied to the four case studies presented in section 3.1 are also compared (Table 3). Some of the viability constraints such as profitability constraints are common to the four case studies, while others such as food security are specific to French Guiana and Solomon Islands. The ecological constraints also differ between structured models in Bay of Biscay or Northern prawn fishery where viability relies on precautionary thresholds for stock biomass while more stylized models in French Guiana or Solomon Islands are based on biodiversity metrics. Mathematical details regarding these viability constraints are also provided in Appendices A.3, A.4, A.5 and A.6.

\subsection{Ecoviability scenarios}

As illustrated in figure 1 for the example of the Bay of Biscay and in figure 2 for French Guiana case, eco-viable strategies satisfying dynamics in equation (1) and objectives specified in equation (10) were identified for the four case studies. The blue diamond lines represent the estimated historical paths while the viability thresholds are indicated in red triangle lines. The envelop of all possible simulated trajectories accounting for the uncertainties is represented by the dark dotted lines and the grey areas include $95 \%$ of the trajectories. The green (full) line within the grey zone is one particular trajectory associated with one specific random selection. The shocks underlying figures 1 and 2 are due to the change of fishing efforts induced by ecoviability strategies: for the Bay of Biscay, the change occurs at the beginning of the scenario namely 2009 while, in French Guiana, the efforts are modified in 2011 and then in 2026 as a revision of decisions is applied after 15 years. The figures illustrate how every ecological-economic constraint is satisfied with a very high probability over time despite the complexities and uncertainties affecting the social-ecological system. 


\subsection{Viability performances of scenarios}

The ecological and economic viability probabilities of the status quo (SQS), net present value (NPVS) and ecoviability (EVS) scenarios are displayed and compared for the four case studies in figure 3. The graph shows that the status quo strategies SQS (grey granite dots) as defined in equation (7) do not adequately cope with bio-economic risks in general in the sense that these SQS offer only a low probability of meeting either the socio-economic viability constraint for Bay of Biscay and French Guiana or both ecological and economic constraints for Solomon Islands. The Northern prawn fishery is the only case displaying good scores from the viewpoint of both ecological and economic risks since viability probabilities are close to $100 \%$.

We also note that, in all case studies, ecoviability strategies EVS (blue degraded dots) reduce ecological and economic risks, as compared to the SQS. The mitigation of ecological and economic risks through ecoviability strategies EVS is not surprising since this EVS relies on the maximization of the ecoviability probability. However, the magnitude of the viability gains between EVS and SQS is not straightforward and varies according to the case study. In the example of the Bay of Biscay fishery, the EVS leads to a strong increase in the probability that socio-economic constraints will be complied with. This improvement is slightly smaller for the French Guiana fishery. In Solomon Islands, the EVS leads to the strongest gain in the management of both ecological and socio-economic risks. In the Northern prawn fishery, the viability benefits are limited because the SQS already performs well as already pointed out. The viability probability metrics thus provide informative and synthetic multi-attribute criteria to grade the case studies in terms of EBFM. Moreover, the improvement associated with lowering bio-economic and ecosystem risks decreases with the level of regulations already in place in these fisheries: the Northern Prawn and the Bay of Biscay fisheries which are characterized by higher levels of regulation than the French Guiana and Solomons Islands fisheries show lower bio-economic and ecosystem risk reductions than those two other fisheries. This finding is likely due to the fact that the regulatory frameworks already in place have been successful at reducing some elements of these economic and/or ecological risks. For instance, fisheries in the Bay of Biscay are managed by targeting MSY (Maximum Sustainable Yield) (ICES, 2009), while the Gulf of Carpenteria prawn fishery is managed with a MEY (Maximum Economic Yield) goal 
Ecoviability

(Gourguet et al., 2014).

\subsection{Synergy or tradeoff between risk and economic expectations}

The trade-offs between ecoviability and expected economic scores are investigated in figure 4. More specifically, the figure compares the scenarios according to both their ecoviavility probability and their mean economic performance in terms of net present values. From its very definition, the ecoviability strategies EVS provide the largest probability for the fisheries to be eco-viable. More interestingly, we note in figure 4 a) focusing on the two cases of small-scale fisheries (French Guiana and Solomon Islands) that these EVS strategies also involve an increase in mean annual economic performance of the fishery as compared to the status quo SQS. French Guiana and Solomon Islands therefore appear to offer potential win-win strategies compared to the current situations. In contrast, as displayed in figure 4 b) focusing on large scale fisheries, the pursuit of ecoviability strategies in the Northern prawn fishery entails a trade-off between co-viability and expected economic performance: meeting the inter-annual economic constraint of positive profits in the Northern prawn fishery can only be achieved through a reduction in the net present value. The case of Bay of Biscay is intermediary in the sense that adopting an EVS strategy is a 'win-noloss' situation as compared to the SQS because enhancing the bio-economic viability is not detrimental to net present value. The global trade-off is even more apparent when comparing the ecoviability strategies with the strategy aimed at maximizing the Net Present Value of profits in the fishery (NPVS, red circle): in all four case studies, the pursuit of ecoviability objectives entails lower mean returns than those which would be achieved by NPVS strategies. Such a trade-off strongly relates to the mean-variance analysis, intensively used in portfolio theory and finance, stressing the antagonism between mitigating risks and promoting the mean (or expected) performances. Such a result exemplifies the idea that an EBFM relying on viability probability criteria and on the mitigation of ecological-economical risks significantly differs from bio-economic maximizing strategies underlying the net present value (NPVS), or economic yield (MEY). 


\subsection{Viable effort or vessels reallocation}

Ecoviability conditions were achieved in each case by adjusting the fleet fishing effort. The control in the Bay of Biscay and the Australian case studies correspond to capacity adjustments in the number of vessels, assuming that the fishing time per vessel remains constant. In both the Solomon and the Guiana case studies, the adjustment takes place at the level of fishing time per vessel or per fisher, assuming that the numbers of vessels/fishers in the fisheries remain stable.

Results differ according to the case studies and constraints. The efforts associated with the ecoviability scenarios for the four case studies are detailed in Doyen et al. (2012); Gourguet et al. (2013, 2014, 2015); Cissé et al. (2013, 2015); Hardy et al. (2013) and summarized in Table 4. It turns out that, in the Bay of Biscay and the Australian cases, ecoviability was achieved by decreasing the capacity of the fleets (decrease in the number of vessels) while in both the Guiana and Solomon examples, bio-economic viability was obtained by both increasing global fishing effort and reallocating it between the different metiers. For instance, in Solomon islands, the viability scenario relies on an important increase of the small-scale (inshore) tuna fishery combined with reductions in sea-cucumber and reef fish fisheries. The global growth of efforts obtained for the ecoviability of the two small-scale fisheries is mainly due to the food security constraint implying increased global fishing intensities in the future. In Solomon Islands, the use of FADs (fish aggregating devices) for skipjack tuna is also favorable to sustainability, stressing the importance of technological innovation in enabling a re-allocation of effort towards more sustainable levels per fish stock (Hardy et al., 2013). More globally, ecoviability induces global reallocations of fishing efforts due to an integrated, multi-species multi-fleet framework well aligned with the holistic objectives of EBFM.

\section{Discussion}

\subsection{Ecoviability is globally well suited to EBFM.}

The central contribution of the paper is to synthesize the potential of the ecoviability modeling approach to operationalize EBFM through different and contrasted case studies. We discuss 
Ecoviability

this assertion with respect to the three items proposed in Pitcher et al. (2009); Ward et al. (2002), namely EBFM principles, EBFM criteria and EBFM implementation, to assess the performances of fisheries with respect to the ecosystem approach.

In terms of EBFM principles, the ecoviability approach globally performs very well. A central feature of the approach is indeed to suppose that ecosystems are complex, dynamic, that their attributes and boundaries are constantly changing, in particular as they relate to the interactions with human uses. Consequently a central aim of ecoviability is to maintain the structure and function of ecosystems, including the biodiversity and productivity of natural systems. Thus it clearly reverses the order of management priorities so that management starts with the ecosystem rather than one target species. We discuss these EBFM principles and issues in a more detailed way in the following subsection 4.2 devoted to models of intermediate complexity. Another principle for EBFM requires human use and values of ecosystems to be central to establishing objectives for the use and management of natural resources. In that respect, the ecoviability approach considers that natural resources are best managed within a system based on a shared vision and a set of ecological and socio-economic targets or constraints developed amongst stakeholders. These multi-attribute and bio-economic principles of EBFM are examined in more detail in the following subsection 4.3 dedicated to sustainability and the triple bottom line. Furthermore, viability management is adaptive through feedback controls especially accounting for uncertainties. This EBFM principle is discussed in the subsection below 4.4 focusing on adaptive management.

In terms of EBFM criteria, the ecoviability approach also performs well. First viability scenarios account for the policy and societal framework at play in every case studies in the sense that management reflects national and international goals, objectives and constraints relating to both conservation and sustainable use. Second, the social, economic and cultural context of the fishery is incorporated by relying on acceptable bio-economic thresholds, tipping points and precautionary boundaries. These dimensions are investigated in the following subsection 4.6 devoted to decision making for fisheries management. In particular ecological values are incorporated through biodiversity or biological viability constraints. This last issue is examined in subsection below 4.5 related to the choice of biodiversity metrics. Furthermore, viable manage- 
Ecoviability

ment relies on the knowledge of utilized species through calibrated and dynamic models. Thus the resource management system is comprehensive and inclusive, based on reliable data and scientific knowledge. Again this is explained in 4.2 dealing with models and complexity. Finally environmental and economic externalities are incorporated especially through stochasticities as elaborated in the subsection 4.4 .

Lastly, regarding EBFM implementation, we cannot assess this meaningfully in the case studies as ecoviability management strategies are not currently in place. French Guiana could provide however a good test-case in that regard in the future, as the implementation of such a strategy is in progress with stakeholders. In the Bay of Biscay, ingredients of ecoviability are also integrated in current management since socio-economic viability constraints are indeed balanced with MSY targets in practical management decision-making (Gourguet et al., 2013). More globally, we discuss possible improvements of the approach in terms of implementation in subsection 4.7 regarding the need to integrate more clearly technical change within the models and scenarios. In subsection 4.8 , we highlight the need to account for other management tools such as quotas or protected areas.

\subsection{Ecoviability allows models of intermediate complexity adapted to EBFM}

The need to take into account the complexity of fisheries management problems especially in the context of EBFM is now broadly recognized (Pahl-Wostl, 2007). Research and the case studies presented here show that this can be done using an integrated, systemic modeling approach that seeks to capture realistic features of marine social-ecological systems, but including only the strictly necessary level of complexity. Such an approach based on multi-species, multi-fleets dynamic models is in line with 'models of intermediate complexity' (MICE) as discussed in Plagányi et al. (2014). MICE models such as those examined here make it possible to address the ecosystem approach at intermediate scales between analytically tractable models used to identify MEY-MSY approaches for single stocks, and higher dimensional and numerical models attempting to capture the 'end-to-end' complexity of the social-ecological system at play. The latter models are usually characterized by a more limited ability to derive the mathematical properties of the system under consideration and may appear as 'black boxes'. MICE being 
Ecoviability

'question-driven', these models will tend to limit the complexity to only account for those components of the social-ecological system required to address specific management issues. The viability approach applied has hitherto largely been focused on stylized/simplified models, to allow for analytical solutions. The applied work presented here demonstrates however the applicability of the viability approach to more realistic representations of fisheries systems, taking account of their complexities and dynamics, notably via numerical simulations.

\subsection{Ecoviability directly deals with sustainability}

The ecoviability modeling framework used here involves an integrated, multi-functional and multi-criteria approach in line with EBFM as in Béné et al. (2001); Doyen et al. (2012); Pereau et al. (2012); Thébaud et al. (2014); Krawczyk et al. (2013); Maynou (2014). A wide range of stakeholders are involved in fisheries and their management, including industrial, artisanal, subsistence and recreational operators, suppliers and workers in related industries, managers, environmentalists, biologists, economists, public decision makers and the general public. Each of these groups has an interest in particular outcomes from fisheries and marine ecosystems, and the performances that are considered desirable by one stakeholder may sound less desirable for another (Hilborn, 2007). Considering this multi-attribute nature of marine fisheries management is a way to guarantee a feasible and acceptable exploitation of aquatic resources, enabling the conditions for sustainability from economic, environmental and social viewpoints as stressed by Pope (1983). The present work is fully aligned with these considerations and the triple bottom line nature (Brooks et al., 2015) of sustainable development, as well as the multi-objective principles stressed in EBFM. Moreover the use of thresholds, precautionary limits, reference or tipping points underlying viability goals results in a simple and operational way to characterize the safety and sustainability of marine ecosystems and fisheries.

Furthermore, by focusing on viability, the models presented in this paper exhibit management strategies and scenarios that account for intergenerational equity. This is another important ingredient of sustainability and sustainable uses of ecosystems underpinning EBFM. As emphasized in Doyen \& Martinet (2012), viability is closely related to the maximin (Rawlsian) approach which gives key insights into intergenerational equity (Heal, 1998). In this respect, 
Ecoviability

the ecoviability strategies and scenarios link present and future performances, the various bioeconomic constraints being equally binding through time. This offers a substantial progress compared to purely economic-oriented strategies such as the NPVS approach, which involves discount factors and generally favor present or short-term performances. This result is particularly illustrated in Gourguet et al. (2013); Cissé et al. (2013); Hardy et al. (2013) related to the case studies examined in this paper.

\subsection{Ecoviability provides an adaptive management with respect to uncer- tainties}

Accounting for uncertainties is a major challenge in ecosystem management. Uncertainties may concern data measurements, ecological dynamics (climate variability, environmental stochasticities) and anthropogenic dynamics (price variability, compliance, etc.). The use of stochastic or probabilistic viability (Doyen \& De Lara, 2010) as detailed in equation (10) provides a solid and rigorous framework for detailed analyses of bio-economic risks, vulnerabilities and ecosystem sustainability. In that vein, Gourguet et al. (2013); Mouysset et al. (2014) stand as important illustrations. In addition, as stochastic viability is based on dynamic programming, it provides closed loop (feedback) controls which enable adaptive strategies and scenarios with respect to possible future states. Adaptability is also possible due to the multi-valued nature of viable management strategies that focus on sets of possible strategies in contrast to optimal control or equilibrium approaches which are usually unique or deterministic, and therefore less flexible.

\subsection{Ecoviability can capture the dynamics of biodiversity}

The ecosystem approach requires the use of biodiversity indicators to assess the ecological states of communities and ecosystems, to track their temporal or spatial changes and finally to identify drivers of changes. Unfortunately the choice of biodiversity metrics remains the subject of numerous debates, with indicators ranging from structural indices, taxonomic or functional indicators to emblematic species. For instance, analyzing the ecological state of lakes, Allen et al. (1999) concluded that the taxonomic diversity index was an ambiguous indicator of biological integrity when used alone. This conclusion may be broadened to structural indicators in the case 
Ecoviability

of marine fish communities (Blanchard et al., 2001). In the case of marine fisheries, the relevance of functional indicators such as the marine trophic level index and the average maximal size in the community to detect some ecosystem effects of fishing can also be questioned (Blanchard et al., 2005).

Regarding ecoviability studies, the species richness index, the marine trophic index and the Simpson indicator have been used, especially in the Guiana (Cissé et al., 2013) and Solomon Islands (Hardy et al., 2013) case studies. For the Bay of Biscay and the Gulf of Carpenteria, the use of indicators associated with the ICES precautionary approach and thresholds for the spawning biomass of fish populations gave important insights into the risks of stock collapse. More generally, it turns out that it is the combination of several ecological indicators, structural and functional, instead of one unique universal biodiversity criterion that seems relevant to evaluate the state of fish megafauna. In this respect, the multi-attribute nature underlying the ecoviability approach has led to major advances strongly connected with criteria requirements for EBFM. Indeed, this multi-criteria approach has been shown to facilitate the comparison of alternative management options in cases where there may be uncertainty, and even disagreement, regarding the selection of not only the indicators of system viability, but also of the thresholds that define the viability space (Thébaud et al., 2014).

\subsection{Ecoviability can represent the short term vs. long term choices}

As demonstrated on figures 1 and 2, the viability approach has allowed the identification of strategies, through reallocation of fishing effort, that create or increase the social-ecological systems viability over a certain period of time. French Guiana and Solomon Islands case studies however also suggest that this viability can be maintained only for a limited number of years: 25 years in French Guiana (Cissé et al., 2015), 35 years in Solomon Islands (Hardy et al., 2013). The two case studies therefore underline the long-term serious problem faced by these territories which are already under intense demographic pressure. Based on the results of these analyses, it appears that the mid-century population will be too high for the resource available, and that even the options/innovations envisaged (e.g. the reallocation of a greater share of the fishing effort toward the tuna resource through the introduction of FADs in Solomon Islands) will eventually 
Ecoviability

reach their limits. The 2050 decade is therefore likely to constitute a tipping point for these islands under the assumption of constant demographic growth and current consumption habits.

Solomon Islands and French Guiana will therefore face important challenges -for which (even) the viability approach seems challenged to find endogenous solutions. The marine resources of these territories have a natural productivity limit which will eventually be reached unless an overall dynamics shift occurs toward another regime. In our case, one possible shift is related to demographics. In Solomon Islands, the hypothesis that such a shift might occur is not totally unrealistic as data indicates that the local demography seems to decrease by $15 \%$ every decade. In French Guiana, however, the recent Census suggests that such a change is not yet happening (Cissé et al., 2013). Such structural constraints, including demographic or technological, stress the need for the ecoviability approach to adopt a more adaptive framework in line with MSE (management strategy evaluation) accounting.

\subsection{Ecoviability can allow underlining the role of technical change}

As noted in Squires \& Vestergaard (2013a,b), technical change in fisheries is a major driver of the sustainability and viability of both fisheries and marine ecosystems and has to be integrated into models aiming at operationalizing EBFM. Technological innovation in the long term will affect not only the dynamics of the system but also alter and modify the ecoviability constraints. These changes will possibly create more viability space in the way it has occurred with the introduction of FADs in Solomon Islands (Hardy et al., 2013). In other cases, however, economic and technological changes may restrict this viability space. Gourguet et al. (2013) for instance show how in the case of the Bay of Biscay, the projected increase in fuel price leads to a decrease in the general viability of the fisheries.

More generally, the very general systemic, mechanistic and dynamic framework underlying equation (1) potentially allows for the introduction of capital dynamics and accounting for technological changes. In that respect, viability works proposed in Doyen \& Martinet (2012) already stress the role played by technical change and substitution between capital and natural resources through the analysis of the Dasgupta-Heal-Solow model. One can also argue that the stochasticity introduced in the models for the economic parameters (prices, costs) is a way to partially 
Ecoviability

capture the technical uncertainties.

\subsection{Ecoviability can rely on many fisheries management tools}

At this stage, it is worth stressing that other management controls should be investigated to address and operationalize EBFM. To keep models simple, the emphasis in this paper has been on fishing effort controls. However, the disadvantages of regulations relying on effort and especially situations of technological creep on fishing effort and fishing mortality are well-known (Wilen, 1979). Consequently, alternative managements based for instance on catch quotas, transferable quotas (Chu, 2009) or marine reserve should be taken into account and examined in the viability, co-viability or ecoviability framework. This has been done in others papers and for other case studies showing that the viability modeling framework is flexible enough to cope with such important management issues for the ecosystem approach. For instance DeLara et al. (2012) deal with harvesting quotas while Pereau et al. (2012) address ITQ management systems. Marine Protected Areas are investigated in Doyen et al. (2007). A simple change enabling the movement from effort and input controls to catch and output controls consists of using Schaeffer or Cobb-Douglas production functions. But this can be more complicated in multi-species and multi-fleet contexts and in situations with non-compliance. In Pereau et al. (2012), the modeling principle is that the effort of agents (fishers or fleets) is adjusted in a rational way (through optimization of rents) to comply with the level of harvesting quotas supply. For the Bay of Biscay and French Guiana case studies, the implementation of such ecoviability goals and approach associated with catch quota regulation strategies is an ongoing work.

\section{Conclusions}

This paper has shown the extent to which the operationalization of EBFM via ecoviability modeling of management strategies and scenarios can be relevant. From a methodological point of view, major advances have recently been made regarding the use of this approach to sustainability issues, in the contexts of multiple dimensional states (multi-species), controls (multi-fleet 
Ecoviability

fishing) and criteria (ecological, social and economic scores). The use of stochastic viability modeling has also promoted a more realistic analysis of ecological-economic risks, vulnerabilities and social-ecological system sustainability. From the decision support viewpoint, identification of eco-viable scenarios in each case study provides important insights in terms of redistribution of fishing effort and conservation measures.

The paper especially highlights that adopting an ecoviability strategy can lead to 'win-win' situations in terms of mitigation of ecological and economical vulnerabilities as compared to the current situation. The paper also stresses some significant differences between more regulated and less regulated fisheries when comparing a viability strategy to the current state (status quo) in terms of economic expectation (mean) and risk (variance). For small scale fisheries, ecoviability turns out also to be a 'win-win' option as compared to the current situation. By contrast, a trade-off between economic expected value and risks is identified for large scale and regulated fisheries. In other words, implementing an ecoviability strategy for large scale and already regulated fisheries could be more difficult because some stakeholders could be reluctant to adopt such a strategy based on bio-economic risk mitigation.

Many stimulating challenges remain. The study of social-ecological system resilience using the tools of viability analysis appears particularly fruitful (Béné et al., 2001; Deffuant \& Gilbert, 2011) due to the insights it brings into recovery and restoration issues, and the ability of fisheries to cope with shocks. Moreover, a refined account of governance (Gutierrez et al., 2011) and EBFM implementation issues through game theory in the context of multi-agent viability also appears very promising. Doyen \& Pereau (2012); Pereau et al. (2012); Hardy et al. (2016) for instance show that coordination strategies or structures (cooperative, community-based management or transferable quota market for large scale fisheries) between agents may improve the bio-economic viability by inducing relevant changes in fishing efforts of different fleets. Although the models in the current examples focus on ecological and economic objectives, the viability models can also accommodate more social indicators as for instance in Pereau et al. (2012) where a participation goal for the agents is imposed. Moving from modeling and management based on input control (effort) to a management based on output control (catch) seems appropriate given the current issues in fisheries governance. At this stage, the comparison of ecoviability strategies 
with the MSY- MEY strategies that are commonly put forward at the international level should be strengthened. The development of spatially explicit models, as initiated in Thébaud et al. (2014), which integrate spatial controls of fishing pressure, including e.g. protected areas, is also an important goal for ecoviability modelers with respect to the operationalization of EBFM.

\section{Acknowledgment}

This work has been initially carried out with the financial support of the ANR (French National Research Agency) through the ADHOC program. The support from the Belmont Forum through the funding of the network SEAVIEW, the IHP (Institut Henri Poincaré) through the organization of the trimester 'mathematics of bio-economics' in the framework of Mathematics of Planet Earth 2013 Initiative as well as the research projects VOGUE and ECOPE (PIG CNRS) are also gratefully acknowledged.

\section{References}

Allen, A.P., Whittier, T.R., Kaufmann, P.R., Larsen, D.P., O'Connor, R.J., Hughes, R.M., Stemberger, R.S., Dixit, S.S., Brinkhurst, R.O., Herlihy, A.T., Paulsen, S.G. (1999) Concordance of taxonomic richness patterns across multiple assemblages in lakes of the northeastern United States. Canadian Journal of Fisheries and Aquatic Sciences, 56(5), 739-747.

Aubin, J-P. (1990) A survey of viability theory. SIAM Journal on Control and Optimization, 28(4), 749-788.

Baumgartner, S., Quaas, M.F. (2009) Ecological-economic viability as a criterion of strong sustainability under uncertainty. Ecological Economics, 68 (7), 2008-2020.

Banks, R., Clarke, S., Staples, D., Souter, D. (2012) Australia Northern prawn fishery: Public Comment Draft Report. MRAG Americas Inc, p. 397.

Béné, C., Doyen, L., and Gabay D. (2001) A viability analysis for a bio-economic model. Ecological Economics, 36, 385-396. 
Blanchard, F. (2001) Dynamics of harvested demersal fish communities: analysis of the species diversity in the Bay of Biscay (Atlantic Ocean) and in the Gulf of Lions (Mediterranean Sea). Aquatic Living Resources, 14(1), 29-40.

Blanchard, J.L., Dulvy, N.K., Jennings, S., Ellis, J.E., Pinnegar, J.K., Tidd, A., Kell, L.T. (2005) Do climate and fishing influence size-based indicators of Celtic Sea fish community structure? ICES Journal of Marine Science: Journal du Conseil, 62(3), 405-411.

Brewer, T. D. (2011) Coral reef fish value chains in Solomon Islands: Market opportunities and market effects on fish stocks. ARC Centre of Excellence for Coral Reef Studies, James Cook University.

Brooks, K., Schirmer, J., Pascoe, S., Triantafillos, L., Jebreen, E., Cannard, T., Dichmont, C. M. (2015) Selecting and assessing social objectives for Australian fisheries management. Marine Policy, 53, 111-122.

Burke, L., Reytar, K., Spalding, M. D. (2012) Reefs at Risk Revisited in the Coral Triangle, World Resources Institute, Washington.

Butchart, S., Walpole, M., Collen, B., van Strien, A., Scharlemann, J., Almond, R., Baillie, J., Bomhard, B., Brown, C., Bruno, J., Carpenter, K. E., Carr, G. M., Chanson, J., Chenery, A. M., Csirke, J., Davidson, N. C., Dentener, F., Foster, M., Galli, A., Galloway, J. N., Genovesi, P., Gregory, R. D., Hockings, M., Kapos, V., Lamarque, J.-F., Leverington, F., Loh, J., McGeoch, M. A., McRae, L., Minasyan, A., Morcillo, M. H., Oldfield, T. E. E., Pauly, D., Quader, S., Revenga, C., Sauer, J. R., Skolnik, B., Spear, D., Stanwell-Smith, D., Stuart, S. N., Symes, A.,Tierney, M., Tyrrell, T. D., Vié, J.-C., Watson, R. (2010) Global Biodiversity: Indicators of Recent Declines. Science, 328(5982), 1164-1168.

Chu, C. (2009) Thirty years later: the global growth of ITQs and their influence on stock status in marine fisheries, Fish and Fisheries, 10(2), 1467-2979.

Cissé, A. A., Gourguet, S., Blanchard, F., Doyen, L., Pereau, J.-C. (2013) A bio-economic model for the viable management of the coastal fishery in French Guiana. Environmental and Development Economics, 18(3), 245-269. 
Cissé, A. A., Blanchard, F., Guyader, O. (2014) Sustainability of tropical small-scale fisheries: Integrated assessment in French Guiana. Marine Policy, 44, 397 - 405.

Cissé, A., Blanchard, F., Doyen, L., Pereau, J.-C. (2015) Ecoviability for small-scale fisheries in the context of food security constraints. Ecological Economics, 119, 39-52.

Clark, C. W. (1990) Mathematical Bioeconomics, second edn. New York: Wiley.

Clark, W. C., Mangel, M. (2000) Dynamic State Variable Models in Ecology: Methods and Applications, Oxford Series in Ecology and Evolution.

Cury, P., Mullon, C., Garcia, S., \& Shannon, L. J. (2005) Viability theory for an ecosystem approach to fisheries. ICES Journal of Marine Science, 62(3), 577-584.

Darby, C.D., Flatman, S. (1994) Virtual Population Analysis: Version 3.1 (Windows-DOS) In: User Guide Vol. 1. Information Technology Series, MAFF Directorate of Fisheries Research, Lowestoft, pp. 85.

Deffuant, G., Gilbert, N. (2011) Viability and Resilience of Complex Systems. Springer.

DeLara, M., Doyen, L., Guilbaud, T., Rochet, M.-J. (2007) Is a management framework based on spawning-stock biomass indicators sustainable? A viability approach. ICES Journal of Marine Science, 64, 761-767.

De Lara, M., Ocana Anaya, E., Oliveros-Ramos, R., Tam, J. (2012) Ecosystem Viable Yields. Environmental Modeling \& Assessment, 17(6), 565-575.

Doyen, L., DeLara, M., Ferrari, J., Pelletier, D. (2007) Sustainability of exploited marine ecosystems through protected areas: A viability model and a coral reef case study. Ecological Modelling, 208(2), 353-366.

DeLara, M., \& Doyen, L. (2008) Sustainable Management of Natural Resources: Mathematical Models and Methods. Springer.

Doyen, L., DeLara, M. (2010) Stochastic viability and dynamic programming, Systems and Control Letters. 59, 10, 629-634. 
Doyen, L., Martinet, V. (2012) Maximin, Viability and Sustainability. Journal of Economic Dynamics and Control, 36(9), 1414-1430.

Doyen, L., Pereau, J.-C. (2012) Sustainable coalitions in the commons. Mathematical Social Sciences, 63(1), 57-64.

Doyen, L., Thébaud, O., Martinet, V., Gourguet, S., Béné, C., Bertignac, M., Fifas, S., Blanchard, F. (2012) Stochastic viability to ecosystem-based management of multi-species fisheries. Ecological Economics, 75, 32-42.

Doyen, L., Cissé, A., Gourguet, S., Mouysset, L., Hardy, P.-Y., Béné, C., Blanchard, F., Jiguet, F., Pereau, J.-C. and Thébaud, O. (2013) Ecological-economic modeling for the sustainable management of biodiversity. Computational Management Science, 10, 353-364.

Eisenack, K., Scheffran, J., Kropp, J.P. (2006) Viability analysis of management frameworks for fisheries. Environmental Modeling Assessment, 11, 69-79.

FAO (2003) The ecosystem approach to fisheries. FAO Technical Guidelines for Responsible Fisheries 4, Suppl. 2. FAO. 112 pp.

FAO (2013) FAO Statistical Yearbook 2013, FAO, Rome.

Godfray, H. C. J., Beddington, J. R., Crute, I. R., Haddad, L., Lawrence, D., Muir, J. F., Pretty, J., Robinson, S., Thomas, S. M., Toulmin, C. (2010) Food Security: The Challenge of Feeding 9 Billion People. Science, 327(5967), 812-818.

Gourguet, S., Macher, C., Doyen, L., Guyader, O., Thébaud, O. (2013) Bio-economic modeling for the viable management of mixed fisheries. Fisheries Research, 140, 46-62.

Gourguet, S., Thébaud, O., Dichmont, C., Jennings, S., Little, L. R., Pascoe, S., Deng, R. A., Doyen, L. (2014) Risk versus Economic Performance in a Mixed Fishery. Ecological Economics, 99, 110-120.

Gourguet, S., Thébaud, O., Jennings, S., Little, L. R., Dichmont C. M., Pascoe, S., Deng, R. A., Doyen, L. (2015) The Cost of Co-viability in the Australian Northern prawn fishery. Environmental Modeling and Assessment, 1-19. 
Govan, H. et al. (2009). Status and potential of locally-managed marine areas in the South Pacific: meeting nature conservation and sustainable livelihood targets through wide-spread implementation of LMMAs. SPREP/WWF/WorldFish-Reefbase/CRISP.

Green, A., Lokani, P., Atu W., Ramohia, P., Thomas, P., et al. (2006) Solomon Islands Marine Assessment: Technical report of survey conducted May 13 to June 17, 2004. 106, The Nature Conservancy, Brisbane.

Gutiérrez, N.L., Hilborn, R., Defeo, O. (2011) Leadership, social capital and incentives promote successful fisheries. Nature, 470, 386-389.

Hardy, P-Y., Doyen, L., Béné, C., Schwartz, A.-M. (2013) Food security-environment conservation nexus: a case study of Solomon Islands' small-scale fisheries. Environmental Development, $8,38-56$.

Hardy, P-Y., Doyen, L. Béné, C., Mills, D. (2016) Viability and resilience of small-scale fisheries through cooperative arrangements. Environmental and Development Economics, 21, 6, 713 741.

Heal, G. (1998) Valuing the Future, Economic Theory and Sustainability. Columbia University Press, New York.

Hilborn, R. (2007) Future directions in ecosystem based fisheries management: A personal perspective. Fisheries Research, 108, 235-239.

ICES (2009) Report of the working group on the assessment of southern shelf stocks of hake, monk and megrim (WGHMM). ICES Headquarters, Copenhagen, p. 537.

Jennings, S. (2005) Indicators to support an ecosystem approach to fisheries, Fish and Fisheries, $6,212-232$.

Krawczyk, J. A., Pharo, A., Serea, O. S., Sinclair, S. (2013) Computation of viability kernels: A case study of by-catch fisheries. Computational Management Science, 10(4), 365-396. 
Langley, A., Hampton, J. (2008) Stock assessment of skypjack tuna in the western and central pacific ocean. Oceanic Fisheries Programme, Secretariat of the Pacific Community, New Caledonia.

Leopold, M. (2004) Poisson de mer de Guyane, Guide Illustré. Quae.

Maynou, F. (2014) Coviability analysis of Western Mediterranean fisheries under MSY scenarios for 2020. ICES Journal of Marine Science, 71, 7, 1563-1571.

Martinet, V., Thébaud, O., Doyen, L. (2007) Defining viable recovery paths towards sustainable fisheries. Ecological Economics, 64, 411-422.

Millenium Ecosystem Assessment (2005) Ecosystems and human well-being, Island Press, Washington, DC.

Milton, D. A., Zhou, S., Fry, G. C., Dell, Q. (2008) Risk assessment and mitigation for sea snakes caught in the Northern prawn fishery. Final report on FRDC Project 2005/051. CSIRO, Cleveland, p. 123.

Morris, W. F. and Doak, D. F. (2003) Quantitative Conservation Biology: Theory and Practice of Population Viability Analysis. Sinauer Associates.

Mouysset, L., Doyen, L., Jiguet, F. (2014) Co-viability of farmland biodiversity and agriculture. Conservation Biology, 28(1), 187-201.

Mullon, C., Curry, P., Shannon, L. (2004) Viability model of trophic interactions in marine ecosystems. Natural Resource Modeling, 17(1), 27-58.

Pahl-Wostl C. (2007) Requirements for Adaptive Water Management. In Pahl-Wostl, Kabat and Möltgen (eds): Adaptive and Integrated Water Management. Coping with Complexity and Uncertainty, Springer Verlag, 2007

Pereau, J.-C., Doyen, L., Little, R. and Thébaud O. (2012) The triple bottom line: Meeting ecological, economic and social goals with individual transferable quotas. Journal of Environmental Economics and Management, 63, 419-434. 
Pikitch, E. K., Santora, C., Babcock, E. A., Bakun, A., Bonfil, R., Conover, D. O., Dayton, P., Doukakis, P., Fluharty, D., Heneman, B., Houde, E. D., Link, J., Livingston, P. A., Mangel, M., McAllister, M. K., Pope, J., Sainsbury, K. J. (2004) Ecosystem-Based Fishery Management. Science, 305, 5682, 346-347.

Pitcher, T. J., Kalikoski, D., Short, K., Varkey, D. \& Ganapathiraju, P. (2009) An evaluation of progress in implementing ecosystem-based management of fisheries in 33 countries. Marine Policy, 33 (2), 223-232.

Plagànyi, É. (2007) Models for an ecosystem approach to fisheries (No. 477). Food \& Agriculture Organisation, Rome.

Plagànyi, É., Punt, A. E, Hillary, R., Morello, E .B., Thébaud, O., Hutton, T., Pillans, R. D., Thorson, J. T., Fulton, E. A, Smith, A. D. M., Smith, F., Bayliss, P., Haywood, M., Lyne, V. and Rothlisberg, P. C. (2014) Multispecies fisheries management and conservation: tactical applications using models of intermediate complexity. Fish and Fisheries, 15(1), 1-22.

Pope, J.G. (1983) Fisheries resource management theory and practice. Proceedings of the conference of Fisheries Research Division.

Punt, A. E., Deng, R. A., Dichmont, C. M., Kompas, T., Venables, W. N., Zhou, S., Pascoe, S., Hutton, T., Kenyon, R., van der Velde, T., and Kienzle, M. (2010) Integrating size-structured assessment and bioeconomic management advice in Australian Northern prawn fishery. ICES Journal of Marine Science, doi:10.1093/icesjms/fsq037.

Rice, J., Garcia, S. (2011) Fisheries, Food Security, Biodiversity and Climate Change. ICES Journal of Marine Science, 68, 1343-1353.

Sanchirico, J. N., Smith, M. D., Lipton, D. W. (2008) An empirical approach to ecosystem-based management. Ecological Economics, 64, 586-596.

Sanogo, C., Raissi, N., Miled, S.B., Jerry, C. (2013) A Viability Analysis of Fishery Controlled by Investment Rate. Acta Biotheoretica, 61(3), 341-52. 
Schuhbauer, A., Sumaila, U. R. (2016) Economic viability and small-scale fisheries - A review. Ecological Economics, 124: 69-75.

Shepherd, J.G. (1999) Extended survivors analysis: an improved method for the analysis of catch-at-age data and abundance indices. ICES Journal of Marine Science, 56, 584-59.

Squires, D. \& Vestergaard, N. (2013) Technical Change and The Commons. The Review of Economics and Statistics, MIT Press, 95(5), 1769-1787.

Squires, D. \& Vestergaard, N. (2013) Technical change in fisheries. Marine Policy, 42, 286-292.

Thébaud, O., Smith, T., Doyen, L., Planque, B., Lample, M., Mahevas, S., Quaas, M., Mullon, C., Vermard, Y., Innes, J. (2013) Building ecological-economic models and scenarios of marine resource systems: workshop report. Marine Policy, 43, 382-386.

Thébaud, O., Ellis, N., Little, L.R., Doyen, L., Marriott, R. (2014) Viability trade-offs in the evaluation of strategies to manage recreational fishing in a marine park. Ecological Indicators, $46,59-69$.

Ward, T., Tarte, D., Heger, E., Short, K. (2002) Policy proposals and operational guidance for ecosystem-based management of marine capture fisheries. Worldwide fund for nature. Sydney, Australia.

Wilen, J. (1979) Fisherman behaviour and the design of efficient fisheries regulation programs, J. Fish. Res. Board Can, 36: 855-858.

WorldFish Center (2010) Community-based adaptive resource management in Solomon Islands: lessons learned, The WorlFish Center, Penang. 12 p. http://www.worldfishcenter.org/content/community-based-adaptive-resource-management-solomon-islands-lessons-learned 


\section{List of Tables}

1 Main common features and differences of the four fisheries. SSF: Small Scale fishery; IF: Industrial fishery; NPF: Northern prawn fishery. Notation ++ means a high level. Notation + means a weak level. Notation 0 means a nil level. . . . .

2 State space formulation: model features in terms of state, control, mechanisms and number of parameters for the four fisheries. FG: French Guiana, BoB: Bay of Biscay, NPF: Northern Prawn Fishery, SI: Solomon Islands.

3 Viability constraints and number of parameters taken into account in the viability metrics for the four case studies. Notation $\mathrm{x}$ means yes. Source for ICES precautionary limits http://standardgraphs.ices.dk/stockList.aspx and FAO

4 Ecoviability efforts changes as compared to status quo at the end of the scenario period for the four case studies. Notation $\nearrow$ means an increase and $\nearrow \nearrow$ means a strong increase. Notation $\searrow$ means a decrease and $\searrow \searrow$ means a strong decrease. 


\begin{tabular}{|c|c|c|c|c|}
\hline Case study & French Guiana & Bay of Biscay & Gulf Carpenteria & Solomon Islands \\
\hline Notation & FG & $\mathrm{BoB}$ & $\mathrm{NPF}$ & SI \\
\hline Scale & SSF & IF & IF & SSF \\
\hline Data & ++ & ++ & ++ & + \\
\hline Targeted biodiversity & $\begin{array}{c}++ \\
(\approx 30 \text { species })\end{array}$ & $\begin{array}{c}++ \\
(\approx 10 \text { species })\end{array}$ & $\begin{array}{c}+ \\
(4 \text { prawn species })\end{array}$ & $\begin{array}{c}++ \\
(\approx 100 \text { species })\end{array}$ \\
\hline Trophic Interactions & ++ & + & 0 & ++ \\
\hline Metier diversity & + & + & 0 & + \\
\hline Technical Interactions & ++ & + & + & + \\
\hline Bycatch & + & + & ++ & 0 \\
\hline Regulation & Limited entry & $\begin{array}{l}\text { TAC (MSY) } \\
\text { selectivity }\end{array}$ & $\begin{array}{c}\text { Limited entry (MEY) } \\
\text { Closure }\end{array}$ & \\
\hline Food security issue & + & 0 & 0 & ++ \\
\hline
\end{tabular}

Table 1 


\section{Source \\ States $x(t)$ \\ Control (effort) $e(t)$}

Maximum age or size structured $A$

Time step $\Delta t$

Trophic interactions

Biological uncertainties

Economic uncertainties

Species growth rates $r_{i}$

Species recruitment parameters

Species mean weight $v$

Species proportions of mature individuals

Species interactions $s_{i j}$

Species mortality rates $M_{i}$

Catchability $q_{i, k, a}$

Species discards $d_{i, k}$

Initial states $x\left(t_{0}\right)$

Initial effort $e\left(t_{0}\right)$
FG

Cissé et al. (2015)
14 fish species

(fishing duration)

month

$+$

$+$

0

14

13

$14 \times 14$

$13 \times 4$

0

14

4
$\mathrm{BoB}$

Gourguet et al. (2013) 3 fish species

16

(number of vessels)

9

year

0

$+$

3

$3 \times 9$

$3 \times 9$

0

$3 \times 9$

$3 \times 16 \times 9$

$3 \times 16 \times 9$

$3 \times 9$

16
$\mathrm{NPF}$

Gourguet et al. (2015) Hardy et al. (2013) 4 fish species

(number of vessels)

41

week

0

$+$

$+$

$3 \times 4$

$3+4 * 41$

$4 \times 41$

0
3

$1+3 \times 2 \times 41 \times 52$

0

$3+2 * 41$

1
SI

8 fish groups

(fishing duration)

week

$+$

0

8

$6 x 6+2$

$3 \times 8$

0

8

Table 2 


Constraints
Number of parameters $\quad \begin{array}{ccccc}\text { FG } & \text { BoB } & \text { NPF } & \text { SI } \\ \text { ICES precautionary limits } B_{\mathrm{pa}} & & \mathrm{x} & \mathrm{x} & \\ \text { Targeted species richness } & \mathrm{x} & & & \mathrm{x} \\ \text { Non valuable by-catch species } & & & \mathrm{x} & \mathrm{x} \\ \text { Food security } & \mathrm{x} & & & \mathrm{x} \\ \text { Profitability } & \mathrm{x} & \mathrm{x} & \mathrm{x} & \mathrm{x} \\ \text { Species trophic levels } T_{i} & 13 & 0 & 0 & 8 \\ \text { Species prices } p_{i} & 13 & 3 \mathrm{x} 9 & 2+2^{*} 41 & 8 \\ \text { Fleet variable costs } c_{k}^{v} & 4 & 16 & 3 & 3 \\ \text { Fleet fixed costs } c_{k}^{f} & 4 & 16 & 1 & 3 \\ \text { Human demographic growth } & 1 & 0 & 0 & 1 \\ \text { Replicates for stochasticity } & 100 & 1000 & 1000 & 1 \\ \text { Table 3 } & & & & \end{array}$


$\begin{array}{llll}\text { FG } & \text { BoB } & \text { NPF } & \text { SI }\end{array}$

Effort 1 (canot créole) (nephrops trawlers) (prawn trawlers) (sea cucumber)

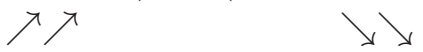

Effort 2 (canot améliorié) (fish trawlers) $\searrow \searrow$ (coral fish) $\searrow \searrow$

Effort $3 \quad$ (pirogue) (sole netters) $\searrow \searrow$ (inshore tuna) $\nearrow \nearrow$

Effort $4 \quad$ (tapouille)

(fish netters) $\nearrow \nearrow$

Total effort

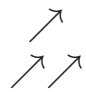

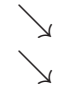

Table 4 


\section{List of Figures}

1 Bio-economic viability scenarios at the horizon $T=2030$ of the Bay of Biscay demersal mixed fishery. Top: Spawning stock biomass of Norway lobster, European hake and Common sole; Bottom; Rents of two specific fleets (in €): nephrops trawlers $(12-16 \mathrm{~m})$ and various fish gill netters $(>24 \mathrm{~m})$ fleets. The dark dotted lines and the grey field include $100 \%$ and $95 \%$ of the trajectories, respectively. In red (triangle), the viability constraints; in blue (diamonds), historical data; in green (dark grey) a random trajectory. Source: Gourguet et al. (2013). . . . . . .

2 Bio-economic viability scenarios at the horizon $T=2045$ of the French Guiana small-scale fishery for different bio-economic indicators. The dark dotted lines and the grey field include $100 \%$ and $95 \%$ of the trajectories, respectively. In red (triangle), the viability constraints; in blue (diamonds), historical data; in green (dark grey) a random trajectory. On top: left: Species Richness; right: Marine Trophic index. Second row: Seafood Production. Third and fourth rows: profit of the four fleets. Source: Cissé et al. (2015).

3 Ecological viability probability $\mathbb{P}\left(\right.$ Constraint (3) are fulfilled for $\left.t=t_{0}, . ., T\right)$ versus economic viability probability $\mathbb{P}$ (Constraints (5) are fulfilled for $t=t_{0}, . ., T$ ) for the four case-studies (BoB, FG, NPF, SI) and the three scenarios SQS (disk grey striped), NPVS (red circle with an empty disk), EVS (full disk degraded blue). In every case, the ecoviability scenario EVS performs better, reducing both ecological and economic vulnerabilities. The arrows point to the bio-economic gains in terms of viability, when moving from the status quo to ecoviability strategies. 


\section{Ecoviability}

4 Ratio of expected economic performance (Y-axis) INPV as in equation (11) and ecoviability probability (Xaxis) $\mathbb{P}\left(\right.$ Constraints (3), (5), (4) are fulfilled for $\left.t=t_{0}, . ., T\right)$ as in equation (10) under the three scenarios SQS (full disk grey granite), NPVS (red empty circle), EVS (full disk degraded blue). By definition, the ecoviability scenario EVS performs better with respect to the co-viability probability. Symmetrically, as expected, the NPVS scenario performs better with respect to economic performance. The arrows in a) comparing the status quo and EVS strategies for small scale fisheries (FG, SI) show the bio-economic win-win situation between economic gain and probability of viability. By contrast, the arrows in b) focusing on large scale fisheries show the bio-economic trade-offs between economic gain and probability of viability, comparing the SQS and EVS strategies. . . . . . . . . . . . . . . 
Ecoviability
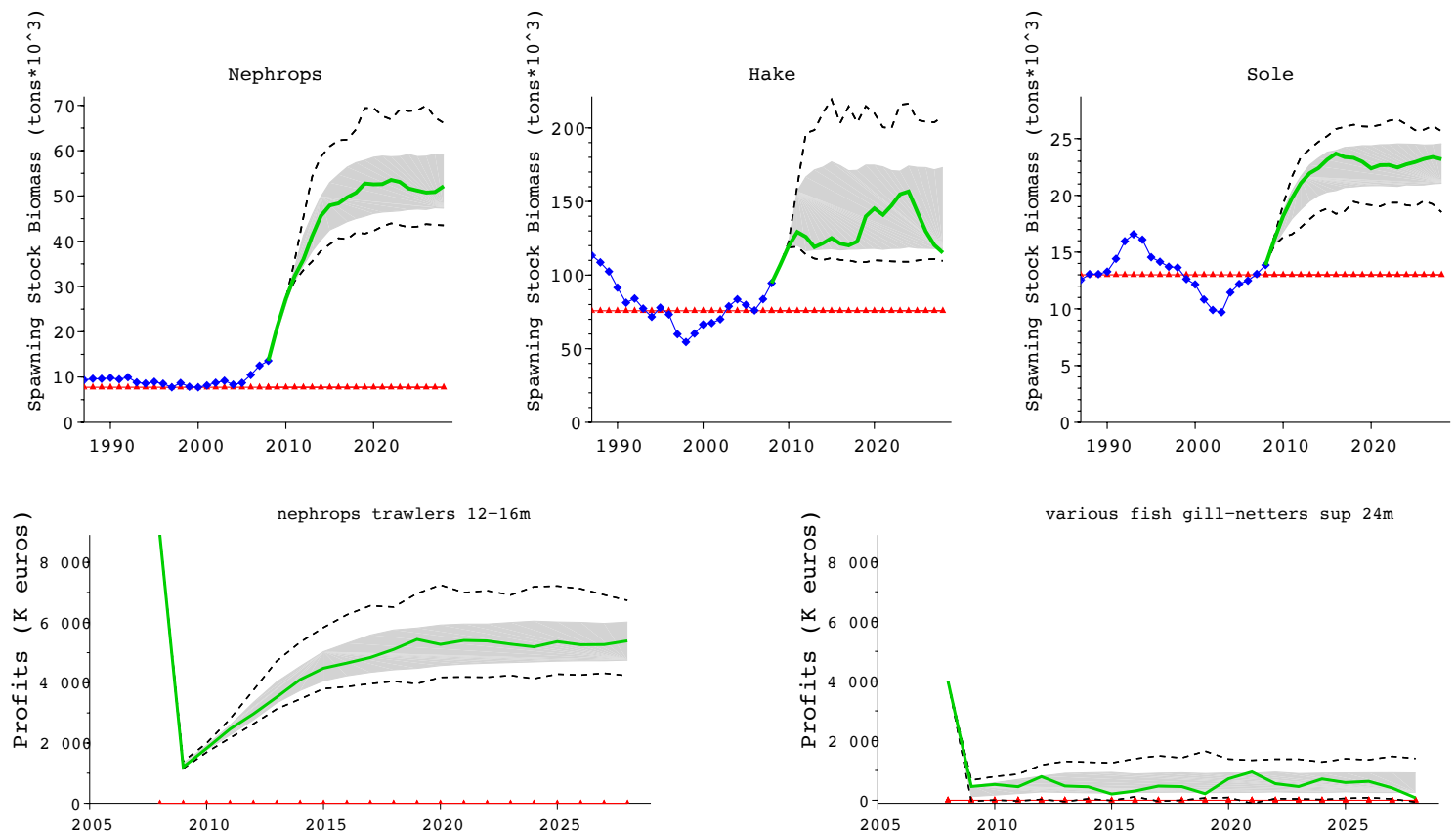

Figure 1 

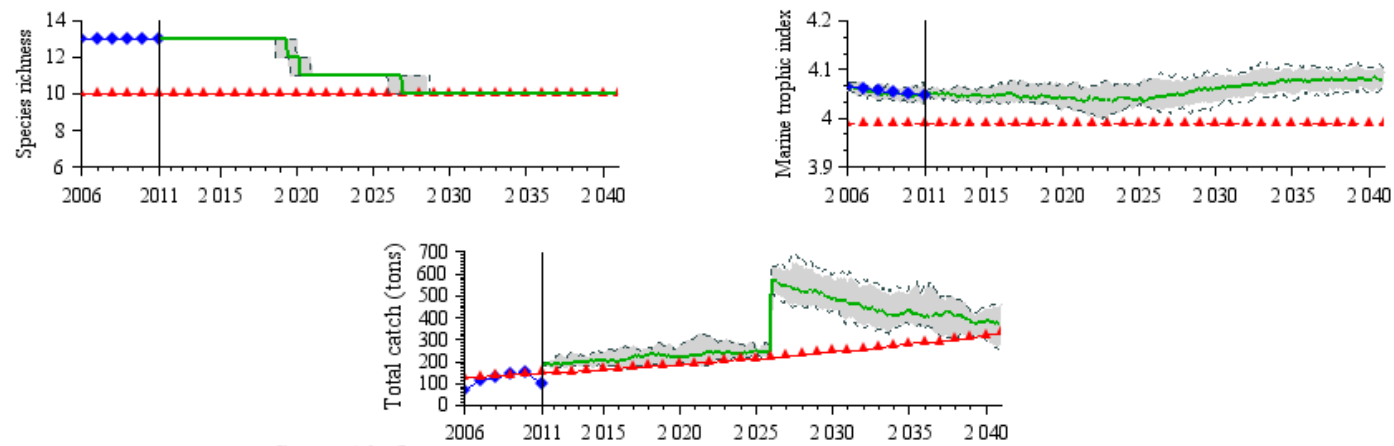

Canots créoles fleet
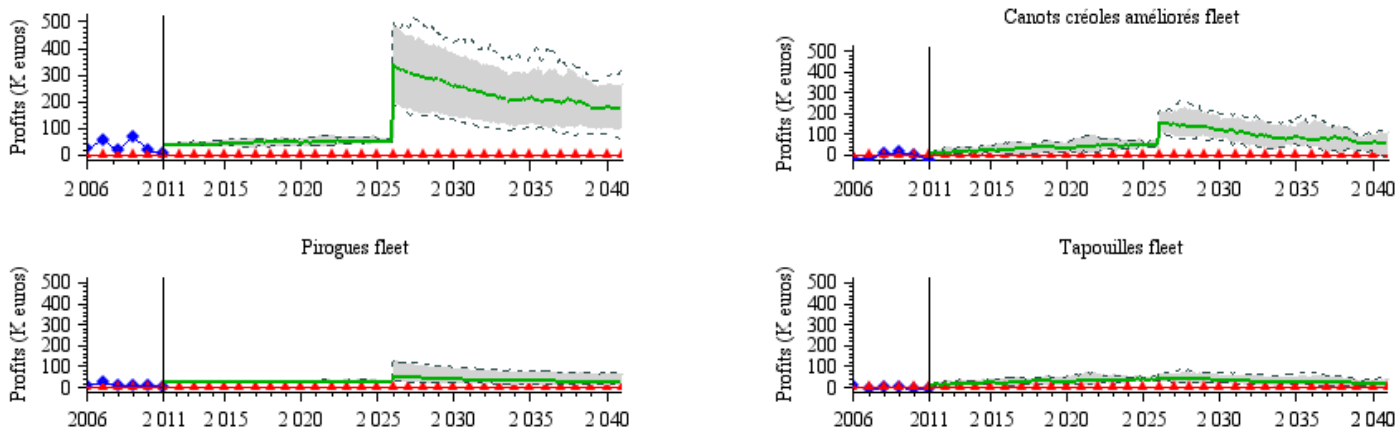

Figure 2 


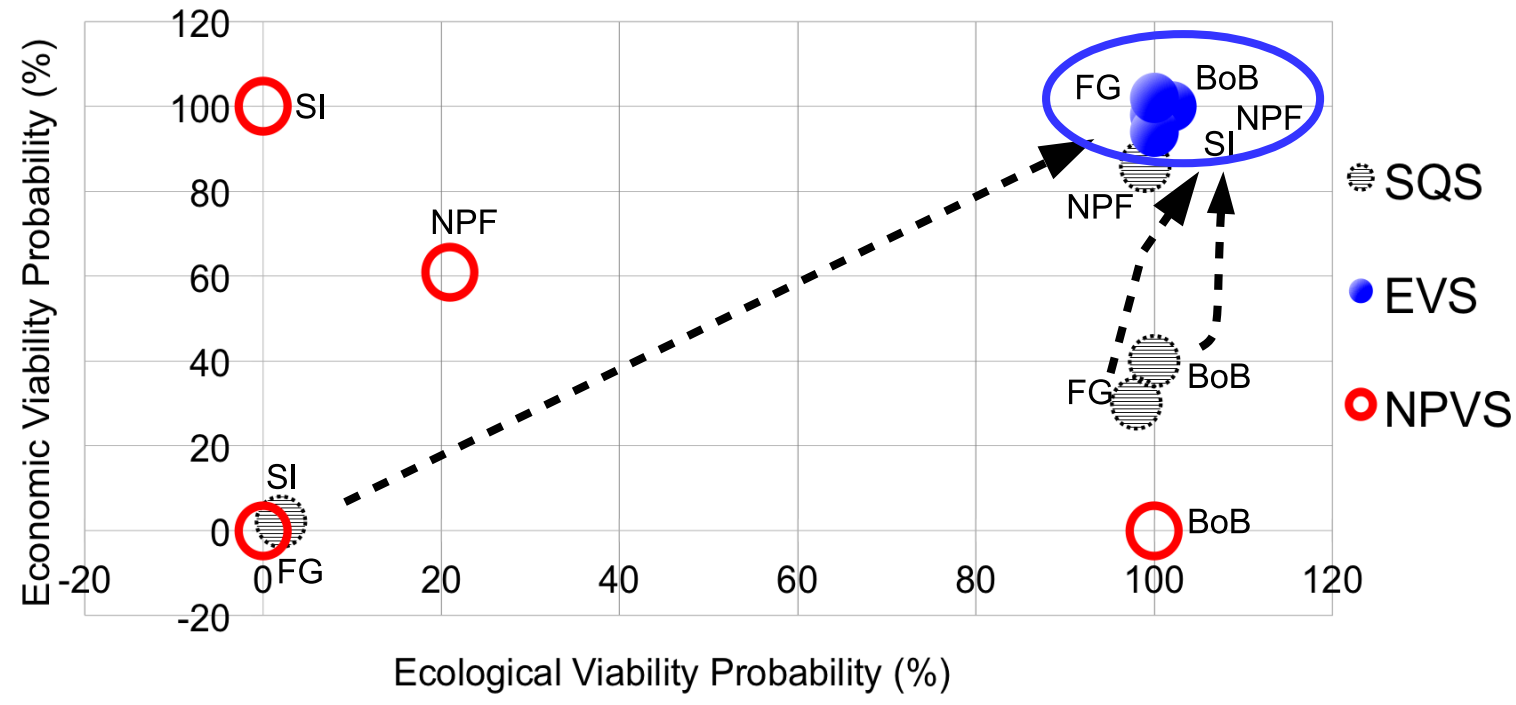

Figure 3 


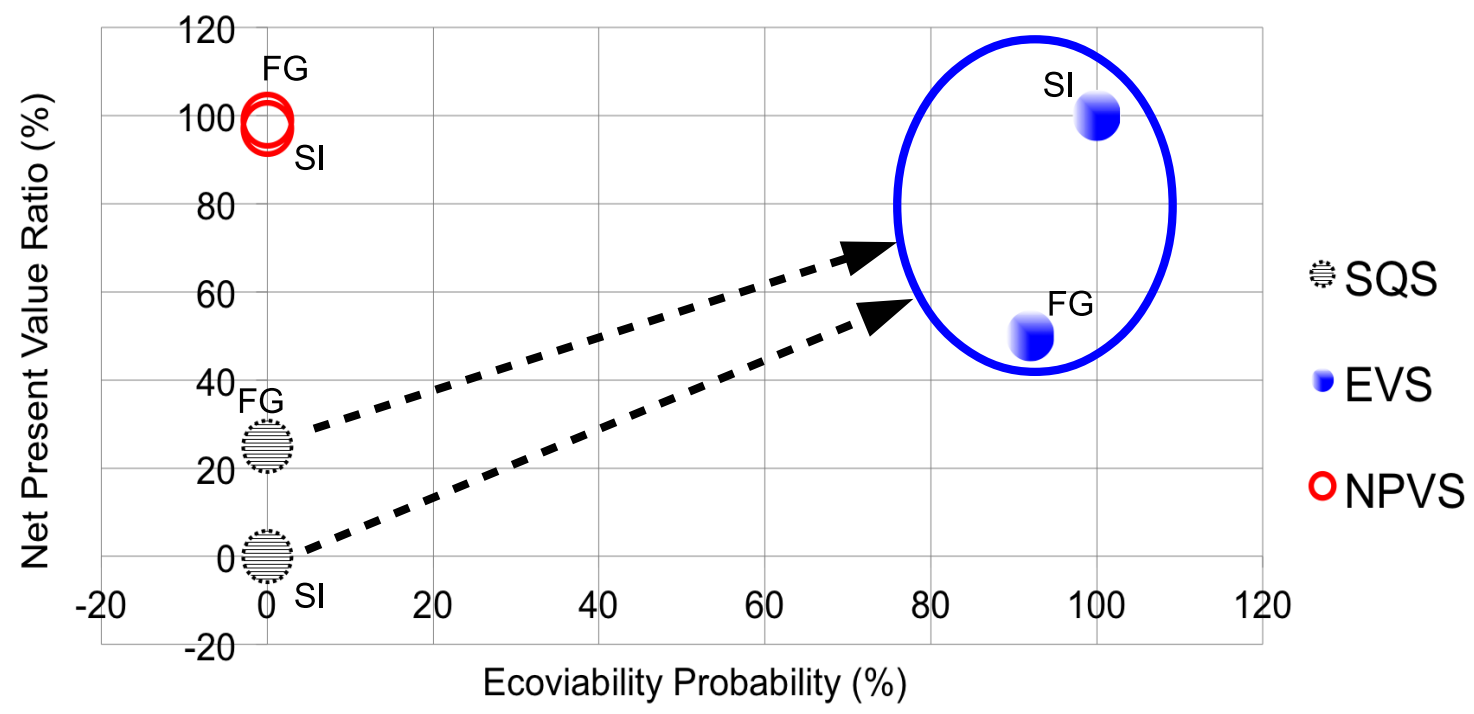

a) Small scale fisheries

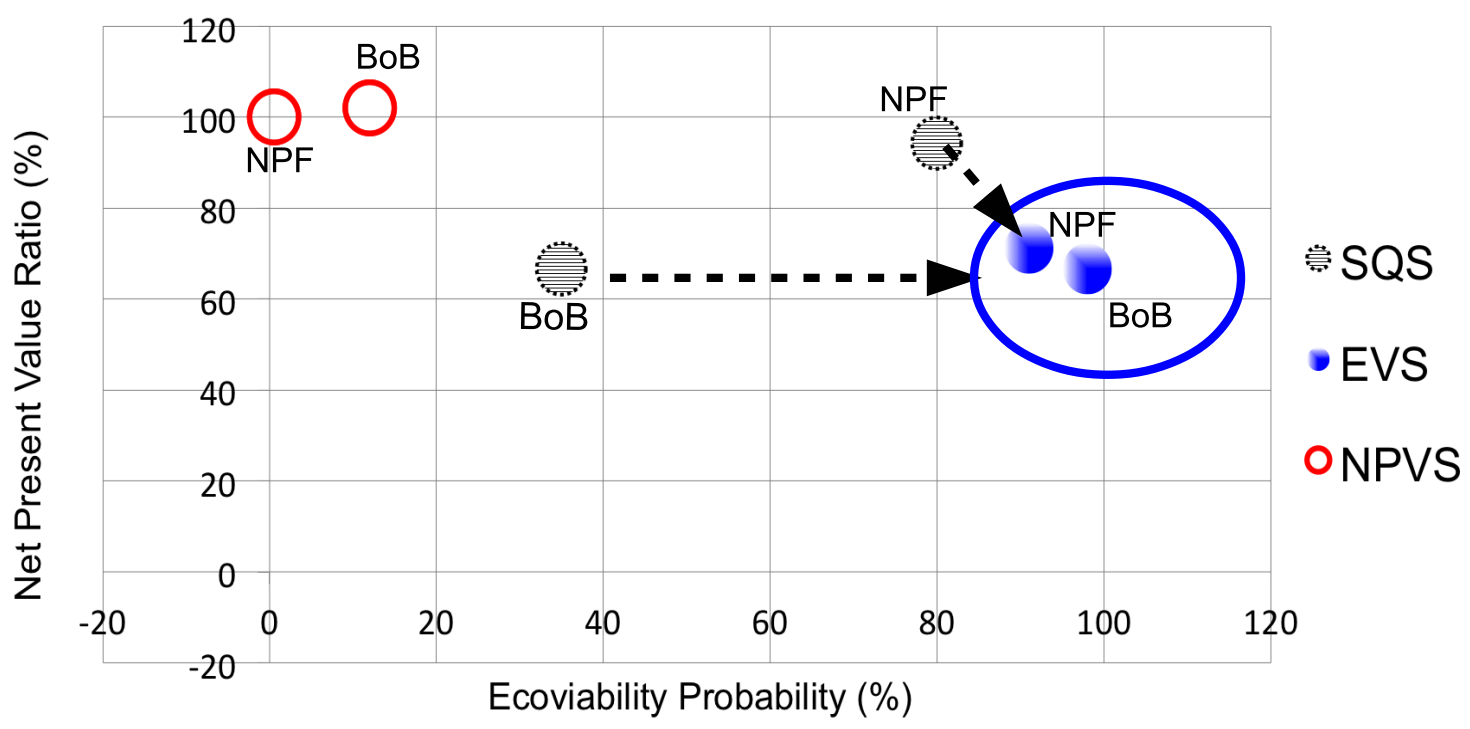

b) Large scale fisheries

Figure 4 


\section{S Appendix}

\section{S.1 Computation of optimal expected value for scenario NPVS}

The normative scenario NPVS defined in (8) based on the maximization of the expected net present value is defined as follows:

$$
\max _{e\left(t_{0}\right), \ldots, e(T)} \mathbb{E}_{\omega}(\operatorname{NPV}(e, \omega))
$$

with the net present value

$$
\operatorname{NPV}(e, \omega)=\sum_{t=t_{0}}^{T} \rho^{t} \sum_{\text {fleets } j} \operatorname{Profit}_{j}\left(x(t), e_{j}(t), \omega(t)\right)
$$

and where $\mathbb{E}$ refers to the expected value of returns with respect to random variables $\omega$ and $\rho$ stands for the discount factor. The numerical approximation of the expected value first relies on the mean over a finite number of replicates of the random variables $\omega($.$) underlying the$ uncertainties. In other words, we consider the following $K$ replicates $\omega_{k}($.$) over time t_{0}, \ldots, T$

$$
\left\{\begin{array}{c}
\omega_{1}\left(t_{0}\right), \ldots, \omega_{1}(T) \\
\vdots \\
\omega_{K}\left(t_{0}\right), \ldots, \omega_{K}(T)
\end{array}\right.
$$

and we approximate the expected value by the mean over the $K$ replicates as follows

$$
\mathbb{E}_{\omega}(\operatorname{NPV}(e, \omega)) \approx \frac{1}{K} \sum_{k=1}^{K} \operatorname{NPV}\left(e, \omega_{k}\right)
$$

Using the scientific software SCILAB available online http://www.scilab.org/en, the replicates are obtained from the function entitled GRAND.

Regarding the way to compute the optimal control $e$, we have to distinguish between the case studies. For Bay of Biscay and NPF case studies, the control is kept fixed during the whole period $t_{0}, . . T$. But for French Guiana and Solomon Islands, the control can change and adapt to the uncertainty at several periods using optimal feedback controls and non anticipative strate- 
gies. For two periods of decision, as explained in the Cissé et al. (2015), closed-loop efforts are solution of the following optimization problem

$$
\max _{e\left(t_{0}\right)} \mathbb{E}_{\omega_{0}}\left[\sum_{t=t_{0}}^{t_{1}-1} \rho^{t-t_{0}} \operatorname{Profit}\left(x(t), e\left(t_{0}\right), \omega_{0}\right)+\max _{e\left(t_{1}, \omega_{0}\right)} \mathbb{E}_{\omega_{1}} \sum_{t=t_{1}}^{T-1} \rho^{t-t_{1}} \operatorname{Profit}\left(x(t), e\left(t_{1}, \omega_{0}\right), \omega_{1}\right)\right]
$$

From a numerical point of view approximating the expected value by the average with respect to the $K=K_{0} * K_{1}$ ( $K_{0}$ in first period; $K_{1}$ in second period) replicates of $\omega$ gives

$$
\max _{e\left(t_{0}\right)}\left\{\begin{array}{c}
\max _{e\left(t_{1}, \omega_{0,1}\right)} \frac{1}{K_{0}} \sum_{\omega_{0}=\omega_{0,1}}^{\omega_{0, K_{0}}}\left[\sum_{t=t_{0}}^{t_{1}-1} \rho^{t-t_{0}} \operatorname{Profit}\left(x(t), e\left(t_{0}\right), \omega_{0}\right)+\frac{1}{K_{1}} \sum_{\omega_{1}=\omega_{1,1}}^{\omega_{1, K_{1}}} \sum_{t=t_{1}}^{T-1} \rho^{t-t_{1}} \operatorname{Profit}\left(x(t), e\left(t_{1}, \omega_{0}\right), \omega_{1}\right)\right] \\
\vdots \\
e\left(t_{1}, \omega_{0, K_{0}}\right)
\end{array}\right.
$$

The optimal control problem above then becomes a more usual mathematical optimization problem where the number of unknown variables is the number of efforts $e$ multiplied by $\left(K_{0}+1\right)$. The feedback (adaptive) fishing effort controls at time $t_{1}$ are given by the different optimal $e\left(t_{1}, \omega_{0}\right)$ associated with the $K_{0}$ replicates of random variables $\omega_{0}$. To approximate this optimal value and identify optimal efforts with the scientific software SCILAB we used the optimizing function entitled OPTIM_GA.

\section{S.2 Computation of optimal viability probability value for scenario EVS}

Efforts in the Ecoviability EVS scenario defined in (10) are computed in a similar way using the fact that the probability is the expected value of an indicator (boolean) function. More specifically, we rewrite the viability probability as follows

$$
\mathbb{P}\left(\text { Constraints are fulfilled for } t=t_{0}, . ., T\right)=\mathbb{E}\left[\prod_{t=t_{0}}^{T} \mathbf{1}_{C}(x(t), e(t), \omega(t))\right]
$$

with the indicator function

$$
\mathbf{1}_{C}(x, e, \omega)= \begin{cases}1 & \text { if constraints are satisfied } \\ 0 & \text { otherwise }\end{cases}
$$


We compute the maximal viability probability as well as optimal controls associated with viability scenario using again the optimizing function in scilab entitled OPTIM_GA 


\section{S.3 Details of the model and data in French Guiana}

Dynamic model: The fishery population dynamics model used in this case is a multi-species, multi-fleet dynamic model in discrete time as in Cissé et al. (2013, 2015). The model accounts for trophic interactions between 13 exploited species and a fourteenth stock aggregating other marine resources. The biomass $x_{i}(t)$ of the species $i$ is assumed to be governed by a dynamic system based on Lotka-Volterra trophic relationships and fishing effort of the different fleets:

$$
x_{i}(t+1)=g_{i}\left(x(t)-h(t), \omega_{i}(t)\right),
$$

with growths and catches by species defined respectively by

$$
\begin{gathered}
g_{i}\left(x_{1}, \ldots, x_{n}, \omega_{i}\right)=x_{i}\left(1+r_{i}-\frac{r_{i}}{K_{i}} x_{i}+\sum_{j \neq i} s_{i, j} x_{j}+\omega_{i}\right) \\
h_{i}(t)=\sum_{k=1}^{m} h_{i, k}(t)=\sum_{k=1}^{m} q_{i, k} e_{k}(t) x_{i}(t) .
\end{gathered}
$$

In equation (17), $r_{i}$ and $K_{i}$ stand respectively for the intrinsic growth rate and the carrying capacity of the species $i . s_{i, j}$ is the trophic effect of species $j$ on species $i$. The noise $\omega_{i}$ captures the environmental stochasticies affecting the growth of each species $i$ at each step $t$. It is assumed that the random variables $\omega_{i}(t)$ follow a Gaussian law, independent and identically distributed $: \omega \rightsquigarrow \mathcal{N}(0, \sigma)$. The control $e_{k}(t)$ in equation (18) represents the fishing effort of fleet $k$ (time spent at sea, in hour) and $q_{i, k}$ measures the catchability of species $i$ by fleet $k$. The number of the fleet $k$ (from $k=1$ to $k=4$ ) corresponds respectively to Canot Créoles, Canot Créoles Améliorés, Pirogues and Tapouille.

Calibration: The model calibration relies on monthly observations of catches and fishing efforts from the landing points all along the coast available from January 2006 to December 2010. Initial stocks, catchabilities, trophic intensities values of the ecosystem as well as the standard deviation of growth were estimated through a least square method. This method

involved minimizing the mean square error between the monthly observed catches $h_{i, k}^{\text {data }}$ and the 
catches $h_{i, k}$ simulated by the model as defined by equation (18):

$$
\min _{x_{0}, s, q, \sigma} \mathbb{E}_{\omega}\left[\sum_{t=\text { January }}^{\text {December }} 2006 \sum_{i=1}^{13} \sum_{k}^{4}\left(h_{i, k}^{\text {data }}(t)-h_{i, k}(t)\right)^{2}\right] .
$$

Figure (S.1) shows how catches generated by the calibrated model fit the historical catches by fleet.

Indicators: Regarding biodiversity metrics, the species richness and marine trophic indicators were selected. Species richness $\mathrm{SR}(t)$ indicates the estimated number of species represented in the ecosystem. In our model, it is assumed that a species disappears whenever its biomass falls under a predetermined viability limit $B_{\lim }$. This threshold $B_{\lim }$ which corresponds to a proxy of the ICES precautionary reference points is here set to $1 / 1000$ of the initial biomass $B_{0}$. The indicator SR is computed as follows:

$$
\mathrm{SR}(t)=\sum_{i} \mathbf{1}_{i}\left(x_{i}(t)\right)
$$

with the boolean function

$$
\mathbf{1}_{i}(x)= \begin{cases}1 & \text { if } \quad x \geq B_{\lim , i} \\ 0 & \text { otherwise }\end{cases}
$$

The marine trophic index $\operatorname{MTI}(t)$ of an ecosystem is computed as follows

$$
\operatorname{MTI}(t)=\frac{1}{N(t)} \sum_{i=1}^{13} T_{i} N_{i}(t) \quad \text { with abundances } N_{i}(t)=\frac{x_{i}(t)}{v_{i}}
$$

where $v_{i}$ is a fixed average weight by species.

The total catches $H(t)$ within the fishery plays the role of food supply:

$$
H(t)=\sum_{k} \sum_{i} h_{i, k}(t)
$$


The profit $\operatorname{Profit}_{k}(t)$ of each fleet $k$ is derived from the landings of each species $h_{i, k}$, the landing prices $p_{i, k}$, fixed $\operatorname{costs} c_{k}^{f}$, variable $\operatorname{costs} c_{k}^{v}$ and the crew share earnings $c_{k}^{L}$ as follows:

$$
\operatorname{Profit}_{k}(t)=\left(1-c_{k}^{L}\right)\left(\sum_{i} p_{i, k} h_{i, k}(t)-c_{k}^{v} e_{k}(t)\right)-c_{k}^{f}
$$

Prices, variable costs and fixed costs are those collected for year 2010. They are assumed to remain unchanged throughout the simulations. Variable costs $c_{k}^{v}$ include fuel consumption, ice, food and lubricants. Equipment depreciation, maintenance and repairs are incorporated in the fixed $\operatorname{costs} c_{k}^{f}$.

Ecoviability constraints: This ecological constraint is about maintaining both the SR index and the MTI above the minimum observed for the status quo scenario SQS defined in equation $(7)$ :

$$
\operatorname{SR}(t) \geq \min _{t=t_{1}, \ldots, T} \operatorname{SR}^{S Q S}(t), \quad \operatorname{MTI}(t) \geq \min _{t=t_{1}, \ldots, T} \operatorname{MTI}^{S Q S}(t) .
$$

The food security constraint is linked to the ability of the fishery to satisfy the local food consumption. Consequently the food security reads

$$
H(t) \geq H(2010) \cdot(1+d)^{t}, \quad \text { for } t=t_{1}, \ldots, T
$$

where $d$ stands for the growth rate of the population and 2010 catches stand for the baseline. To analyze the economic risks, we define the profit constraint for every fleet at any time:

$$
\operatorname{Profit}_{k}(t) \geq 0, \quad \text { for } t=t_{1}, \ldots, T ., \text { for every } k=1, . ., 4 \text {. }
$$




\section{S.4 Details of the model and data in Bay of Biscay}

Dynamic Models: As detailed in Gourguet et al. (2013), population dynamics of the three species included in the analysis (hake, nephrops and sole) were modeled using an age-structured population model. Parameters were derived from stock assessments carried out by ICES (2009) using a virtual population model. The model was then fitted for each species separately, using data on catch and abundance from surveys or derived from commercial cpues. Fish population dynamics are modeled using an age-structured population model derived from the standard fish stock assessment approach. Population dynamics are described on a yearly basis and integrate uncertainties regarding recruitment. The age-structured dynamics of the three species are governed by :

$$
x_{i, a}(t+1)=x_{i, a-1}(t) \exp \left(-M_{i, a-1}-F_{i, a-1}(t)\right), \quad a=2, \ldots, A_{i}-1
$$

where $x_{i, a}(t)$ stands for the abundance of the exploited species $i=1,2,3$ (Nephrops, Hake and Sole, respectively) at age $a=1, \ldots, A_{i}$. Thus the state evolves according to both natural $M_{i, a}$

and total fishing $F_{i, a}(t)$ mortality rates of the species $i$ at age $a$. Total fishing mortality of species $i$ at age $a F_{i, a}$ is derived from the sum of fishing mortality from all 17 sub-fleets:

$$
F_{i, a}(t)=\sum_{k=1}^{17} F_{i, a, k}(t)=\sum_{k=1}^{17} q_{i, a, k} e_{k}\left(t_{0}\right) \mathrm{K}_{k}(t)
$$

where $e_{k}\left(t_{0}\right)$ is the mean value of fishing effort by vessel of sub-fleet $k$ expressed in number of days at sea and $\mathrm{K}_{k}(t)$ is the number of vessels by sub-fleet $k$. The reference year is set at $t_{0}=2008$. The catchability $q_{i, a, k}$ corresponds to the fishing mortality of species $i$ at age $a$ associated with one unit of effort from a vessel of sub-fleet $k$. The parameter values are derived from the ICES databases.

The recruits $x_{i, 1}(t+1)$ for each species are assumed to be uncertain functions of the Spawning Stock index (biomass here) $S S I_{i}(t)$ at time $t$ :

$$
x_{i, 1}(t+1)=\phi_{i}\left(S S I_{i}(t), \omega_{i}(t)\right) .
$$


The Spawning Stock biomass $S S I_{i}(t)$ of the species $i$ is given by:

$$
\operatorname{SSI}_{i}(t)=\sum_{a=1}^{A_{i}} \gamma_{i, a} v_{i, a} x_{i, a}(t)
$$

with $\left(\gamma_{i, a}\right)_{a=1, \ldots, A_{i}}$ the proportions of mature individuals of species $i$ at age $a$ and $\left(v_{i, a}\right)_{a=1, \ldots, A_{i}}$ the weights of individuals of species $i$ at age $a$. In the present case-study, the recruitment relationship of the species is set using an Ockham-Razor function:

$$
\phi_{i}\left(S S I_{i}, \omega_{i}\right)= \begin{cases}\omega_{i} \rightsquigarrow \mathcal{U}_{i} & \text { if } S S I_{i} \geq B_{i}^{\lim }, \\ S S I_{i} \frac{\bar{R}_{i}}{B_{i}^{\lim }} & \text { if } S S I_{i} \leq B_{i}^{\lim } .\end{cases}
$$

Here $\mathcal{U}_{i}$ stands for the uniform distribution relying on the historical time series of recruitment $R_{i}^{t}$ of species $i$ and the notation $\omega_{i} \rightsquigarrow \mathcal{U}_{i}$ means that the random variable $\omega_{i}$ is governed by the uniform probability distribution $\mathcal{U}_{i}$. Threshold $B_{i}^{\lim }$ is the ICES limit reference biomass and $\bar{R}_{i}$ the mean historical recruitment values by species. The three species have different biology and life cycles, therefore their recruitments are assumed to be uncorrelated.

Calibration: Parameters underlying the dynamics (27) and (29) were derived from stock assessments carried out by ICES (2009) using a virtual population model. The model was then fitted for each species separately, using data on catch and abundance from surveys or derived from commercial CPUEs. Figure S.2 displays the comparison between the historical and simulated spawning biomass $S S I_{i}(t)$ for the three species at play.

Indicators: For each period $t$, the exploitation of the three species is described by the catches $h_{i, a, k}(t)$. These catches depend on initial fishing mortalities $F_{i, a, k}\left(t_{0}\right)$ and abundances $x_{i, a}(t)$ through the Baranov catch equation:

$$
h_{i, a, k}(t)=x_{i, a}(t) F_{i, a, k}(t) \frac{1-\exp \left(-M_{i, a}-\sum_{k=1}^{m} F_{i, a, k}(t)\right)}{M_{i, a}+\sum_{k=1}^{m} F_{i, a, k}(t)} .
$$


The gross income from catches of each sub-fleet denoted by $\operatorname{Inc}_{k}(t)$ is then estimated by introducing the market price of the species along with the estimates of discard rates, such that:

$$
\operatorname{Inc}_{k}(t)=\sum_{i} \sum_{a=1}^{A_{i}} p_{i, a}(t) v_{i, a, k} h_{i, a, k}(t)\left(1-d_{i, a, k}\right) .
$$

where $v_{i, a}$ is the mean weight of landed individuals of species $i$ at age $a$ and $d_{i, a, k}$ represents the discard rate of individuals of age $a$ by the sub-fleet $k$. Discard ratios were calibrated on the data available from the ICES working group WGHMM. Prices $p_{i, a}(t)$ correspond to the market value (euros by $\mathrm{kg}$ ) of species $i$ at age $a$ for year $t$ and are assumed to be uncertain. Uncertainties on annual market price by species are introduced through a random price by species following a Gaussian law as:

$$
p_{i}(t) \rightsquigarrow \mathcal{N}\left(\mu_{i}^{P}, \sigma_{i}^{P}\right) .
$$

Gaussian laws are calibrated from ex-vessel prices for the three species for the 2000-2009 period, recorded in French harbours (data from Ifremer, SIH, DPMA). Prices by species $p_{i}(t)$ are assumed to be independent by species and by year. The profit Profit ${ }_{k}$ of a sub-fleet $k$ is estimated as follows:

$$
\operatorname{Profit}_{k}(t)=\left(\operatorname{Inc}_{k}(t)+\alpha_{k} \mathrm{~K}_{k}(t) e_{k}\left(t_{0}\right)\right)\left(1-\tau_{k}\right)-\left(\mathrm{V}_{k}^{f u e l} p_{f u e l}(t) e_{k}\left(t_{0}\right)+c_{k}^{v} e_{k}\left(t_{0}\right)+c_{k}^{f}\right) \mathrm{K}_{k}(t)
$$

Here the parameter $\alpha_{k}$ corresponds to the income per unit of effort of sub-fleet $k$ derived from catches of species not explicitly modelled. We assume that biomass and price of other species are constant, and that the impacts of modelled fleets on these species are relatively negligible. Rate $\tau_{k}$ is the landing cost by sub-fleet as a proportion of the gross income. $\mathrm{V}_{k}^{\text {fuel }}$ corresponds to the volume of fuel (in litres) used by fishing effort unit (i.e. days at sea) for one vessel of sub-fleet $k$ and $p_{\text {fuel }}(t)$ is the fuel price by litre of the year $t$ that can be subjected to projection scenarios. The other variable $\operatorname{cost} c_{k}^{v}$ of a fishing effort unit by a vessel of sub-fleet $k$ includes oil, supplies, ice, bait, gear and equipment $\operatorname{costs}$ while $c_{k}^{f}$ corresponds to the annual costs associated with vessel of the sub-fleet $k$, including maintenance, repair, management and crew costs, fishing firms, licenses, insurance premiums and producer organisation charges. Cost parameter values 
in the model are based on the economic data available for 2008 (Ifremer, SIH, DPMA) and are assumed to be constant over the simulation period.

Ecoviability constraints: Ecological viability is defined as the requirement that the Spawning Stock Biomass of each individual species is maintained above a threshold value. In this study, the thresholds correspond to $B_{i}^{\mathrm{pa}}$, the biomass of precaution of the species $i$ estimated by the International Council for the Exploration of the Sea. The constraint is specified as:

$$
\operatorname{SSI}_{i}(t) \geq B_{i}^{\mathrm{pa}}, \quad i=1,2,3 .
$$

We also consider the economic objective of maintaining positive profits for the sub-fleets over time as follows

$$
\operatorname{Profit}_{k}(t)>0, \quad k=1, \ldots, 16 .
$$




\section{S.5 Details of the model and data in the Northern prawn fishery}

Dynamic Model: As described in Gourguet et al. (2014) and Gourguet et al. (2015), three prawn species in Australia's Northern prawn fishery were modeled explicitly using a size and sex-structured population model (with Ricker stock-recruitment relationship and environmental uncertainties) that operates on a weekly time-step. The parameters of this multi-species population model were estimated using data on catches and effort, catch rates, as well as length frequency data from both surveys and commercial landings (Punt et al., 2010). The dynamics of the three species are governed by:

$$
x_{i}(t+1)=g_{i}\left(x_{i}(t), F_{i}(t), \omega(t)\right), \quad i=1,2,3
$$

where $x_{i}(t)$ is the matrix of abundance $x_{i, \text { sex,l }}(t)$ of the exploited prawn species $i=1,2,3$ (grooved and brown tiger and blue endeavour prawns, respectively) of sex female or male in size-class $l$ alive at the start of time $t$ which corresponds to one time step, i.e. one week. The dynamic function $g_{i}$ accounts for species recruitment and mortality mechanisms of species $i$ as detailed in Punt et al. (2010). $F_{i}(t)$ is the matrix of fishing mortality $F_{i, l}(t)$ of animals of species $i$ and size-class $l$ at time $t$ and is derived from the sum of fishing mortality from the two tiger prawn fishing strategies:

$$
F_{i, l}(t)=\sum_{k=1}^{2} F_{i, l, k}(t)=\sum_{k=1}^{2} q_{i, l, k}(t) e_{k}(t) \mathrm{K}(y(t)),
$$

where $e_{k}(t)$ is the mean value of fishing effort (in days at sea) by vessel associated with tiger prawn fishing strategy $k=1,2$ at time $t$, and $\mathrm{K}(y(t))$ is the number of vessels involved in the fishery during the year $y(t)$ ( which is the year ${ }^{1}$ corresponding to the time $t$ ). Catchability $q_{i, l, k}(t)$ corresponds to the fishing rate of species $i$ in size-class $l$ associated with one unit of fishing effort of fishing strategy $k$ (as in 2010) which depends on week $t$ because the relative availability of species $i$ varies with time. Recruits in the fishery for species $i=1,2,3$ during a 'biological' year are assumed to be related to the spawning stock size index of species $i$ for the previous

\footnotetext{
${ }^{1}$ Year $y(t)$ is a function of week $t$, where weeks are numbered $1, \ldots, 52,53, \ldots, 102,103, \ldots$
} 
year, according to a Ricker stock-recruitment relationship fitted assuming temporally correlated environmental variability and down-weighting recruitments, as described in Punt et al. (2010). The annual spawning stock size indices $S S I_{i}(y(t))$ of the three species $i$ for the year $y(t)$ are calculated as in Punt et al. (2010) and are described by

$$
S_{S} I_{i}(y(t))=\frac{1}{52} \sum_{t=52(y(t)-1)+1}^{52 y(t)} \beta_{i}(t) \sum_{l} \gamma_{i, l} \frac{1-\exp \left(-\left(M_{i}+F_{i, l}(t)\right)\right)}{M_{i}+F_{i, l}(t)} x_{i, \text { female }, l}(t) .
$$

where $x_{i, f e m a l e, l}(t)$ is the abundance of prawns of species $i$ of sex female in size-class $l$ alive at the start of time $t$, and $M_{i}$ is the natural mortality of animals of species $i$. $\beta_{i}(t)$ measures the relative amount of spawning of species $i$ during the time $t$, and $\gamma_{i, l}$ corresponds to the proportion of females of species $i$ in size-class $l$ that are mature.

A fourth prawn species, the white banana prawn is represented without an explicit densitydependence mechanism, due to its highly variable recruitment and in the absence of a defined stock-recruitment relationship. The biomass of this species is thus modeled as a uniform i.i.d. random variable, described by equation (41).

$$
x_{4}(y(t)) \rightsquigarrow \mathcal{U}\left(B_{4}^{-}, B_{4}^{+}\right),
$$

with $x_{4}(y(t))$ the stochastic biomass of white banana prawn for the year $y(t)$, and $B_{4}^{-}$and $B_{4}^{+}$ the uniform law bounds. Numerical values are given in Gourguet et al. (2014).

Indicators: Weekly catches $h_{i, l, k}(t)$ of species $i=1,2,3$ in length-class $l$ by tiger prawn fishing strategies $(k=1,2)$; and annual catches $h_{i=4, k=3}(y(t))$ of prawn species $i=4$ by banana prawn fishing strategy $(k=3)$ for the year $y(t)$ are defined by

$$
\begin{array}{ll}
h_{i, l, k}(t)=\sum_{\text {sex=male }}^{\text {female }} v_{i, \text { sex }, l} x_{i, \text { sex }, l}(t) F_{i, l, k}(t) \frac{1-\exp \left(-M_{i}-\sum_{k=1,2} F_{i, l, k}(t)\right)}{M_{i}+\sum_{k=1,2} F_{i, l, k}(t)} & \\
h_{i, k}(y(t))=q_{i, k} x_{i}(y(t)) e_{k}(y(t)) \mathrm{K}(y(t)) & i=4 ; k=3
\end{array}
$$


with $v_{i, s e x, l}$ the mass of an animal of species $i=1,2,3$ and sex sex in size-class $l$. The annual gross income by fishing strategy $k=1,2,3$ is calculated such that:

$$
\begin{array}{ll}
\operatorname{Inc}_{k}(y(t))=\sum_{t=52(y(t)-1)+1}^{52 y(t)}\left(\sum_{i=1}^{3} \sum_{l} p_{i, l} h_{i, l, k}(t)\right), & i=1,2,3 ; k=1,2 \\
\operatorname{Inc}_{k}(y(t))=p_{i} h_{i, k}(y(t)), & i=4 ; k=3
\end{array}
$$

where $p_{i, l}$ is the average market price per kilogram for animals of species $i=1,2$ and 3 in size-class $l$. The average price per kilogram of prawn species $i=4$ is denoted by $p_{i=4}$. Total annual profit of the whole fishery Profit $(y(t))$ for year $y(t)$ is then formulated as follows:

$\operatorname{Profit}(y(t))=\left(\sum_{k=1}^{3} \operatorname{Inc}_{k}(y(t))\right)\left(1-c^{L}\right)-\left(c^{M} \sum_{k=1}^{3} \sum_{i=1}^{4} h_{i, k}(t)\right)-\left(\sum_{k=1}^{3}\left(c_{k}^{v} e_{k}(y(t))\right)+c^{f}\right) \mathrm{K}(y(t))$

where $c^{L}$ is the share cost of labour (crew are paid a share of the income) and $c^{M}$ is the cost of packaging and gear maintenance (assumed to be proportional to the fishery catch in weight). The other variable cost $c_{k}^{v}$ includes the costs of repair, maintenance, fuel and oil per unit of effort of fishing strategy $k$; while $c^{f}$ is the annual fixed cost by vessel (i.e. those costs that are not related to the level of fishing effort). More details are given in Punt et al. (2010) and Gourguet et al. (2014).

Total annual sea snake catch $h_{\text {seasnake }}(y(t))$ is considered as an indicator of the impacts of fishing on sea snakes. Annual sea snake catches are estimated based on data available in Banks et al. (2012) from linear regressions. To model a progressive adoption over time of more effective Bycatch Reduction Devices (Milton et al., 2008), the coefficient values from the linear regressions are reduced progressively by $8.7 \%$ each year to have a total reduction of $87 \%$ (compared to the initial year) after a period of 10 years. More details are given in Gourguet et al. (2015).

Ecoviability constraints: Ecological viability is defined as the requirement that the spawning stock index of each individual species $i=1,2,3$ is maintained above a threshold value. In this study the thresholds $S S I_{i}^{\mathrm{lim}}$ correspond to $50 \%$ of the 2010 spawning stock size indices, based 
on a precautionary approach. The constraint is specified as:

$$
S_{S I}(y(t)) \geq S_{i}^{\lim }, \quad i=1,2,3
$$

We also consider a sea snake conservation objective which requires maintaining the catch of sea snakes below or equal to a maximum 'allowed' level:

$$
h_{\text {seasnake }}(y(t)) \leq h_{\text {seasnake }}^{\lim }
$$

with $h_{\text {seasnake }}^{\lim }$ the maximum allowed total catch of sea snakes set to the sea snake catch estimated with 2010 (i.e. reference year) effort levels.

The economic objective in this study requires maintaining a minimum total annual profit for the NPF such that:

$$
\operatorname{Profit}(y(t)) \geq \text { Profit }^{\text {lim }}
$$

where Profit ${ }^{\text {lim }}$ is set to $50 \%$ of the 2010 annual profit. 


\section{S.6 Details of the model and data in Solomon Islands}

Dynamic Models: Following Hardy et al. (2013), the state of the socio-ecosystem corresponds to the biomass of eight fish families including the Holothurian $i=1$, Serranidae $i=2$, Lutjanidae $i=3$, Lethrinidae $i=4$, Acanthuridae $i=5$, the Scaridae $i=6$ and others coral-reef fishes $i=7$ while the pelagic family $i=8$ relates to the skypjack tuna and the Scombridae family. The dynamics of the eight fish groups are assumed to be governed by Lotka-Volterra type interactions and by fishing efforts associated with 3 fleets $k$ including the fleet $k=1$ associated with sea cucumber fishing, the fishing of the coral-reef fishes $k=2$ and tuna fishing $k=3$. Thus, the biomass $x_{i}(t+1)$ of family $i$ at time $t+1$ depends on previous stocks' biomasses $x_{i}(t)$, fishing efforts $e_{k}(t)$ and labour intensity $L_{k}(t)$ of fleet $k$ through the relation :

$$
x_{i}(t+1)=x_{i}(t) \cdot\left(1+r_{i}+\sum_{j=1}^{8} s_{i, j} \cdot x_{j}(t)-\sum_{k=1}^{3} q_{i, k} \cdot e_{k}(t) \cdot L_{k}(t)\right)
$$

with $x(t)$ in $\mathrm{kg} / \mathrm{m}^{2}, e_{k}(t)$ in hours/fishers, $L_{k}(t)$ in number of fishers. Parameter $r_{i}$ stands for the intrinsic growth rate of the population $i$ while $s_{i, j}$ is the trophic effect of family $j$ on family $i$. The parameter $q_{i, k}$ measures the catchability on family $i$ of fleet $k$.

The catch $h_{i, k}$ of stock $i$ by fleet $k$ at time $t$ is given by:

$$
h_{i, k}(t)=q_{i, k} \cdot e_{k}(t) \cdot L_{k}(t) \cdot x_{i}(t) \cdot \quad k=1,2,3
$$

The total fishing effort is assumed to grow linearly since 2004 in proportion with the total population of the islands following a yearly demographic rate of $d=2.14 \%$ by year.

$$
L_{k}(t)=L_{k}(2004)(1+d)^{t}
$$

Calibration: For the sea cucumber and coral fish groups, parameters were calibrated based on data extracted from the literature including Green et al. (2006) and FishBase. The parameterization of the model for skipjack was carried out in two steps. First, a Western Pacific assessment (Langley \& Hampton, 2008) was used to estimate the industrial fishery's parameters. 
Then, the model including all fleets (industrial and artisanal) was fitted to data on catches from 1982 to 2006 using a least square method. The free access Scilab software was used for the code and computation of the simulations. The figure S.3 displays the fitness beween simulated and historical catches for the tuna.

Indicators: Species (family) richness SR and the Simpson index SI are used to depict structural aspects of the marine ecosystem. A family is here assumed to become extinct whenever its abundance falls below a minimum threshold set at a certain proportion of its initial biomass $x_{i}(0)$. The Simpson index SI complements the SR index by estimating the probability that two individuals belong to the same family.

The choice of economic indicators, a subsistence index and a cash index, reflects the dual function of fishing in the case study. The subsistence index computed per capita corresponds to the quantity of fish kept by households for self-consumption:

$$
h_{\mathrm{sub}}(t)=\sum_{k} \alpha_{k} \sum_{i} \frac{h_{i, k}(t)}{L_{k}(t)}
$$

where $\alpha_{k}$ represents the shares of the catch kept for self-consumption. The other shares $\left(1-\alpha_{k}\right)$ correspond to the share of fish sold on local or regional markets. Like the subsistence index, the cash index remains per capita:

$$
\operatorname{Profit}(t)=\left(1-\alpha_{k}\right) \cdot \sum_{i} p_{i} \cdot \sum_{k} \frac{h_{i, k}(t)}{L_{k}(t)}
$$

with the prices $p_{i}$ assumed to be fixed and the costs to be null. The proportion of fish retained by households for self-consumption averaged around $60 \%$ (i.e. $40 \%$ sold for cash). We therefore used this value for households' self-consumption of reef fish and tuna, i.e. $\alpha_{3}=\alpha_{2}=60 \%$. In contrast, $\alpha_{1}=0 \%$ as sea cucumber is not consumed but only harvested for cash.

Ecoviability constraints: In this study the ecological constraint relates to the attempt to maintain the various fish families above their respective extinction thresholds (using the Simpson and Species Richness Indexes as indicators), while the economic and social constraints attempt 
to ensure households food and cash security.

The ecological constraints are:

$$
\left\{\begin{array}{l}
\mathrm{SR}(t) \geq 0.9 \mathrm{SR}(2004) \\
\mathrm{SI}(t) \geq 0.9 \mathrm{SI}(2004)
\end{array}\right.
$$

The levels of the two economic constraints (food and cash security) were defined by international standards. The food security constraint relies on a weekly amount of $0.8 \mathrm{~g} / \mathrm{kg}$ protein per person and reads here

$$
h_{\mathrm{sub}}(t) \geq h_{\mathrm{sub}}^{l i m}=2.1 \quad \mathrm{~kg} / \mathrm{hh} / \text { week }
$$

while the second economic constraint relies on the weekly basic need poverty line estimated at $47 \$ S B$ per household

$$
\operatorname{Profit}(t) \geq \text { Profit }^{l i m}=47 \quad \$ S B / \text { hh/week }
$$


(a)

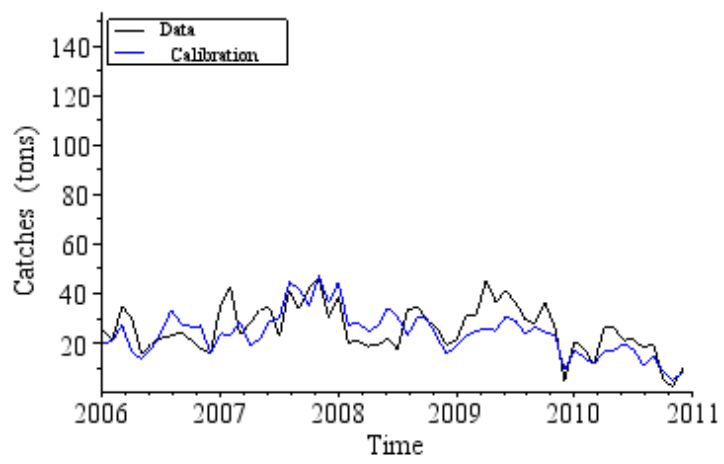

(c)

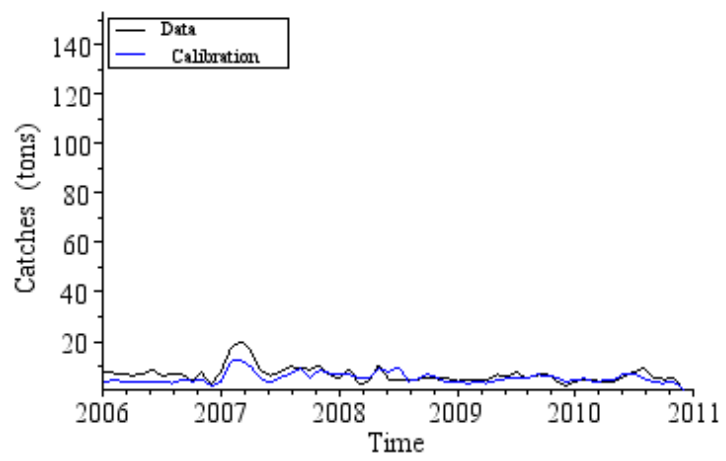

(b)

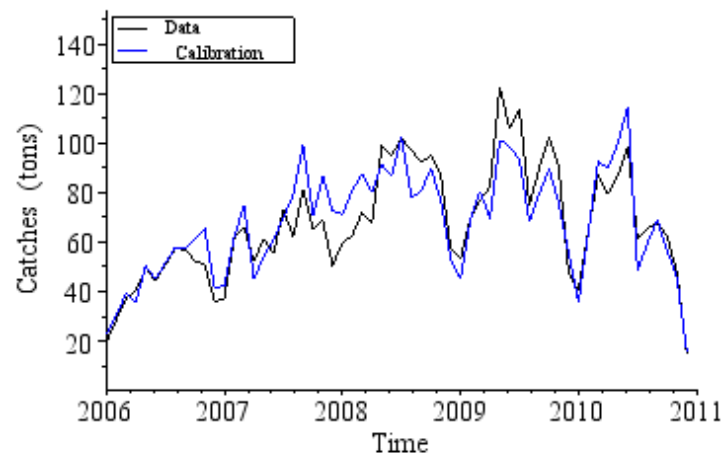

(d)

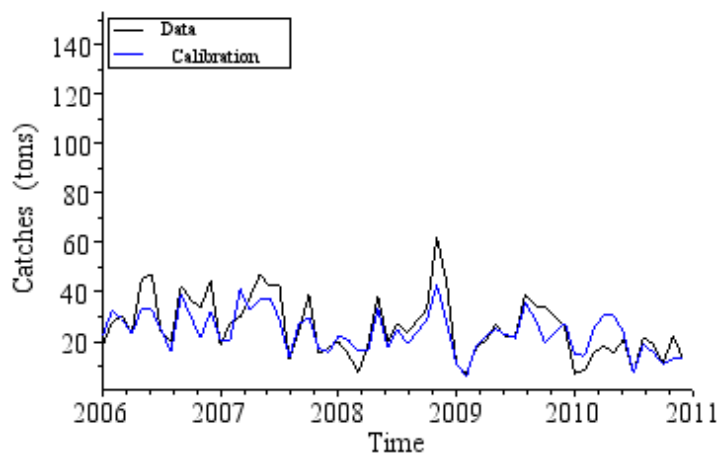

Figure S.1 - French Guiana: Comparison by fleet $k$ between historical catches $\sum_{i} h_{i, k}^{\text {data }}(t)$ and simulated catches $\sum_{i} h_{i, k}(t)$. 

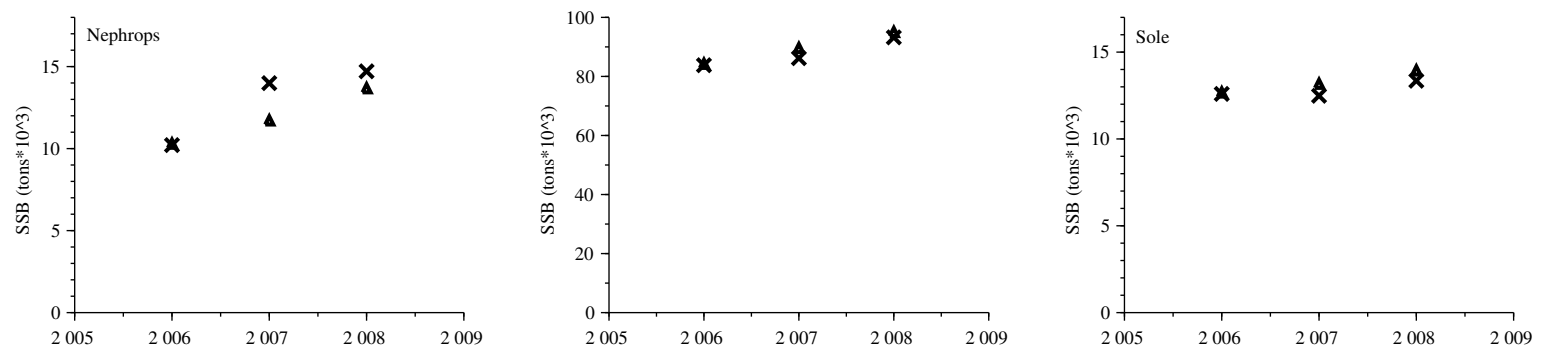

Figure S.2 - Bay of Biscay: Comparison between historical and simulated spawning biomass $S S I_{i}(t)$ for the three species at play over 2006-2008. Crosses stands for the historical values while the triangles stands for the values estimated by the model. 


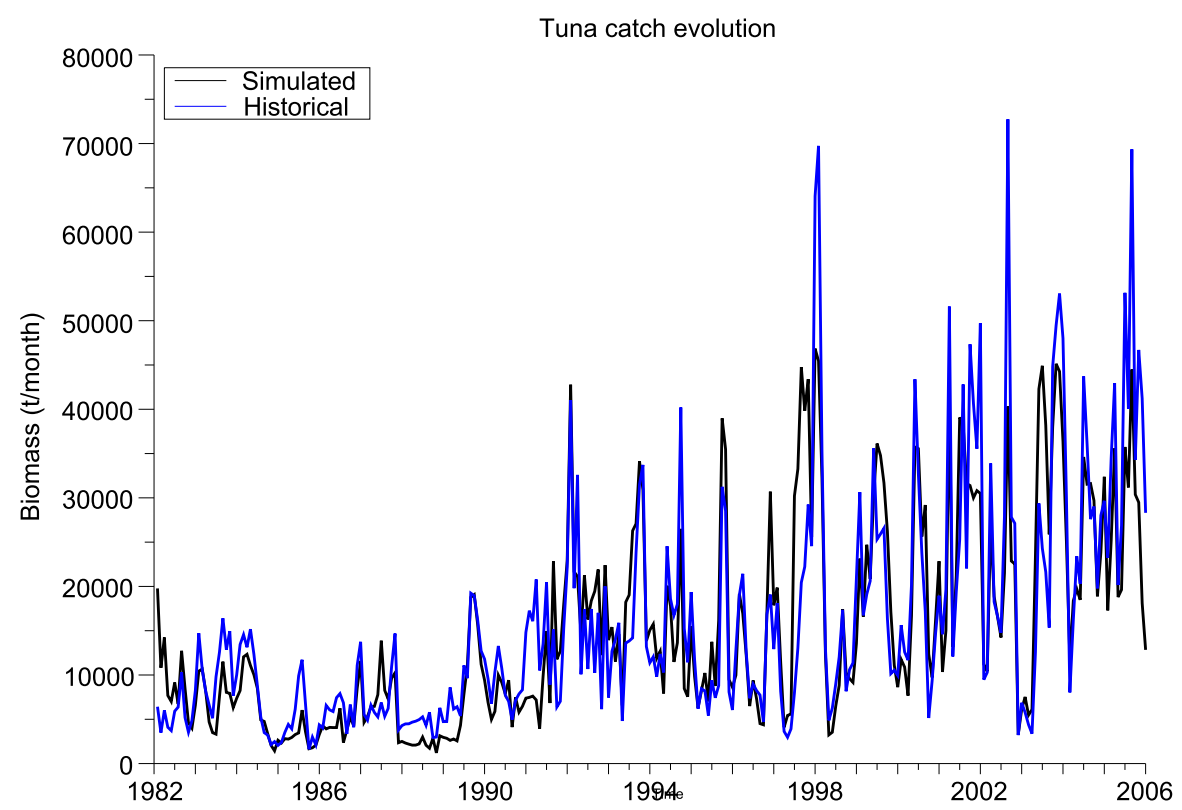

Figure S.3 - Solomon Islands: The historical $h_{8,3}^{\text {data }}(t)$ in blue) and simulated catch $h_{8,3}(t)$ (in black) for the pole and line tuna fishery. 


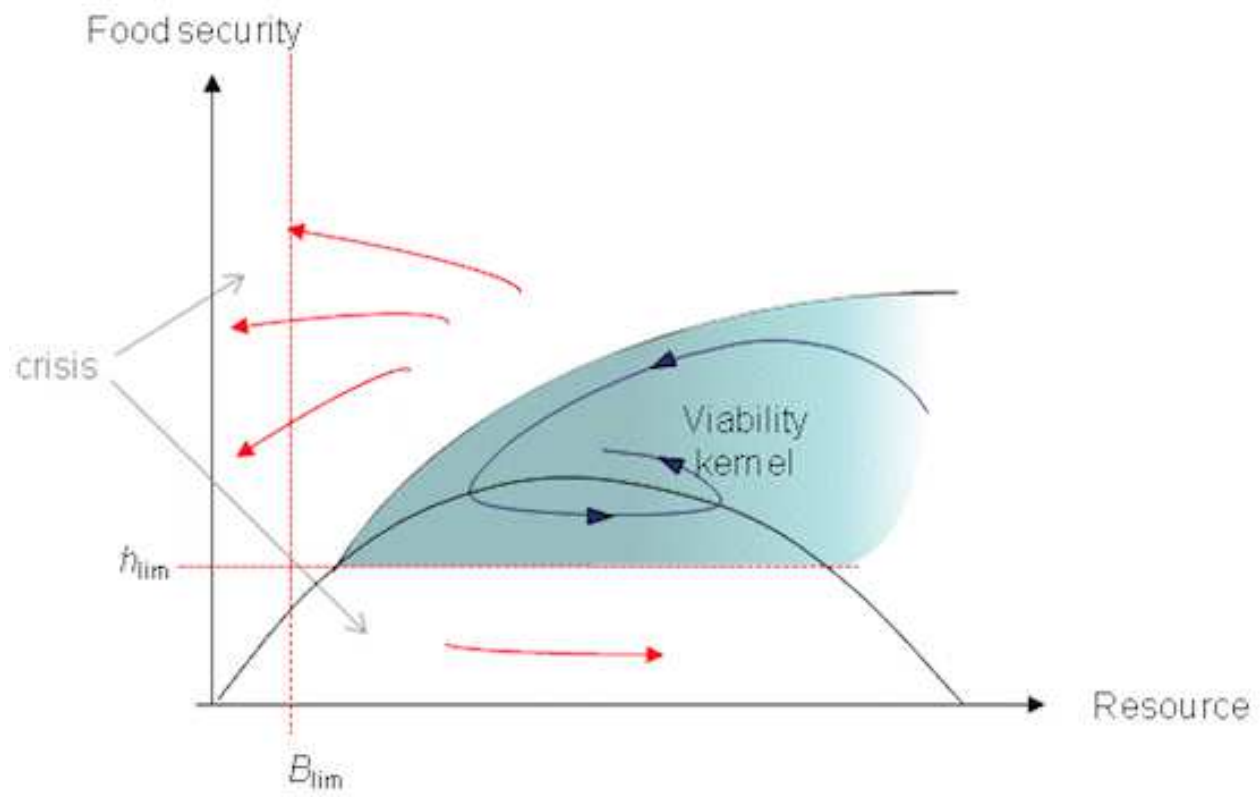

Figure S.4 - Viability kernel and bio-economic viability: In blue the viability kernel represents the set of initial conditions of the system which ensures that the controlled dynamics (illustrated by the system trajectories) will satisfy the viability constraints at any time. In the present case, (for sake of simplicity) we only represent two constraints: the ecological and food security ones (the economic constraint is omitted). These constraints are indicated on the diagram by the two green dotted lines and the associated two thresholds: $B_{\lim }$ and $h_{\text {lim }}$. Below these two thresholds the viability constraints are violated (the system is in crisis). Above the thresholds, for red trajectories, initial conditions are viable at $t=0$ but the dynamics of the system is such that future crisis can not be avoided. Only within the viability kernel is the system viable and will remain so at any time in the future (blue trajectories). 